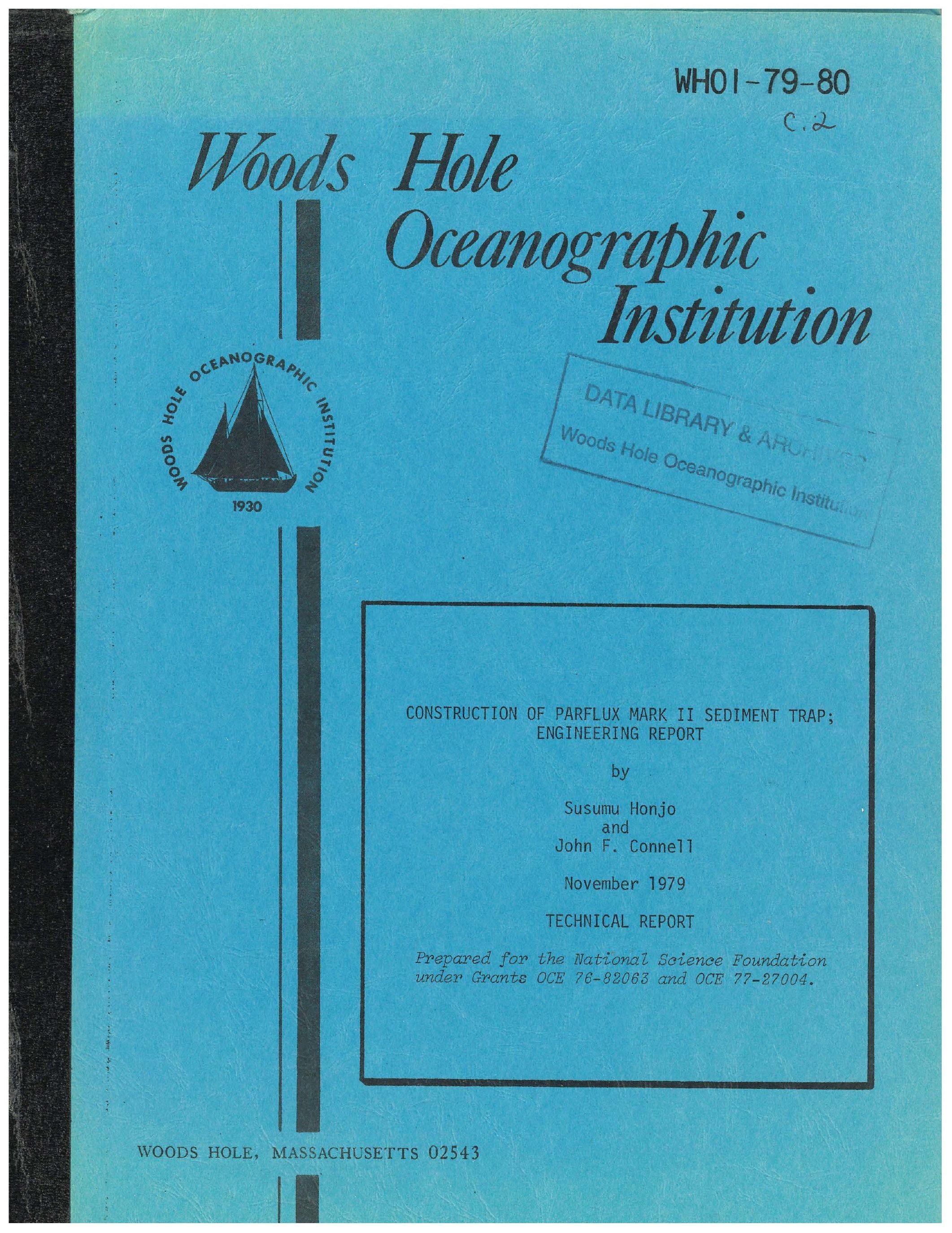


WHOI -79-80

\section{CONSTRUCTION OF PARFLUX MARK II SEDIMENT TRAP; ENGINEERING REPORT}

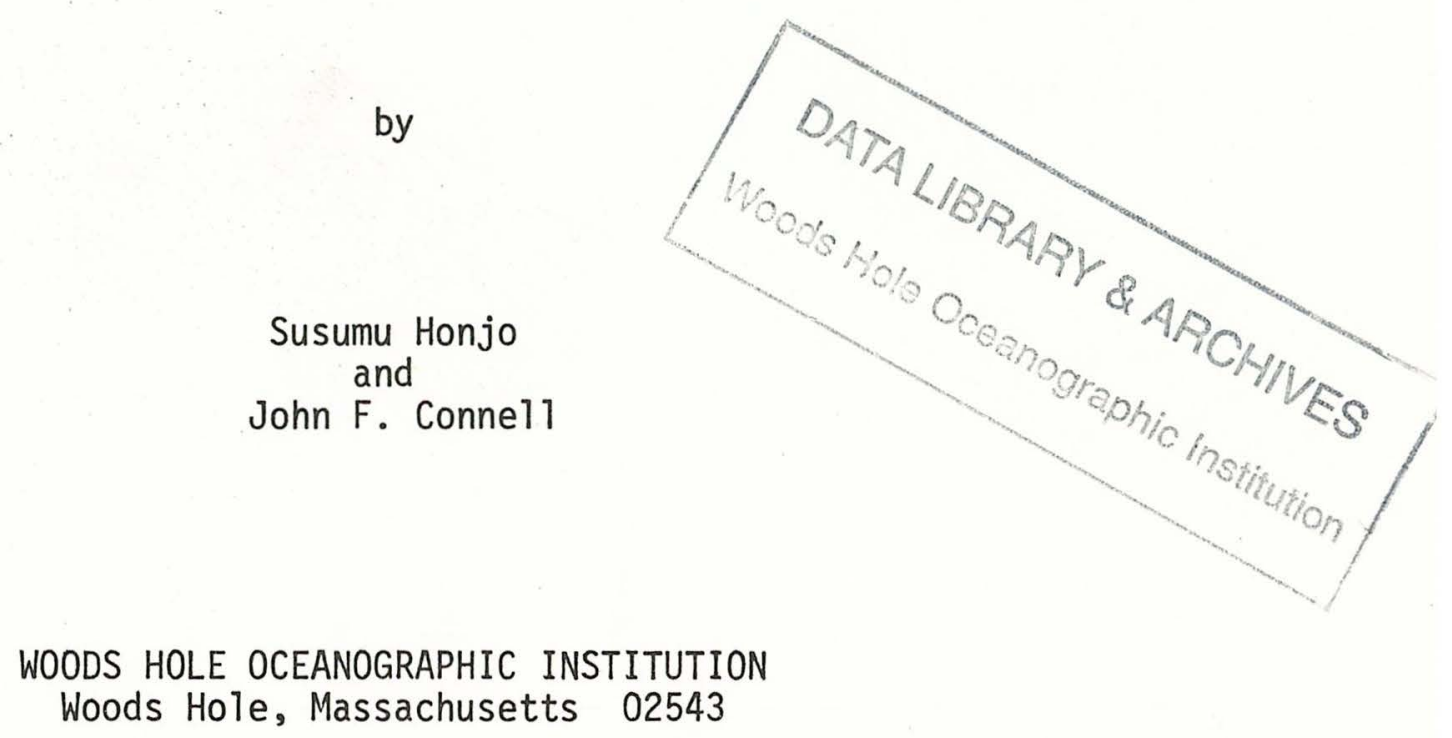

November 1979

TECHNICAL REPORT

Prepared for the National Science Foundation under Grants OCE 76-82063 and OCE 77-27004.

Reproduction in whole or in part is permitted for any purpose of the United States Govermment. This report should be cited as: Woods Hole Oceanographic Institution Technical Report WHOI-79-80.

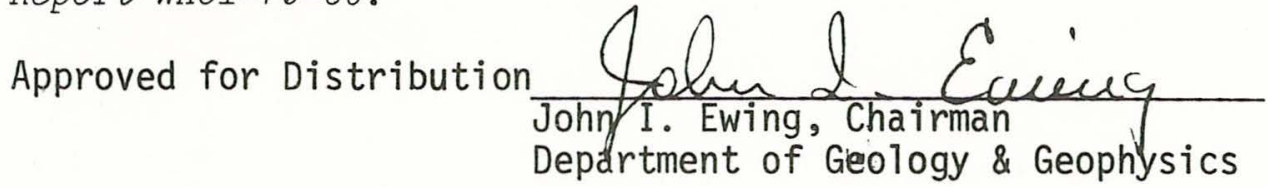




\section{CONTENTS}

$\underline{\text { Page }}$

Abstract 1

Introduction $\quad 2$

Description of PARFLUX Mark II Sediment Trap 3

Honeycomb buffer and funnel 3

Receiving cup mechanism 5

Type S

Type C 11

Electronic Timer 15

Framework 15

Prevention of Corrosion 16

Mooring Array 16

$\begin{array}{ll}\text { Result and Discussion } & 19\end{array}$

$\begin{array}{ll}\text { Acknowledgements } & 21\end{array}$

$\begin{array}{ll}\text { References } & 22\end{array}$

$\begin{array}{ll}\text { Parts List } & 24\end{array}$

Explanation of Plates 37

Appendix 1: Sodium Azide, a hazardous compound 43

Appendix 2: Electronic Timer-Release, detail 47

THE USE OF COMMERCIAL NAMES IN THIS ARTICLE IS FOR IDENTIFICATION PURPOSES ONLY AND DOES NOT CONSTITUTE ENDORSEMENT BY THE WOODS HOLE OCEANOGRAPHIC INSTITUTION. 


\title{
CONSTRUCTION OF PARFLUX MARK II SEDIMENT TRAP; ENGINEERING REPORT
}

by

Susumu Honjo and John F. Connell

\begin{abstract}
A large, open ocean applicable sediment trap has been developed at the Woods Hole Oceanographic Institution in order to assess the fluxes of particles sinking through the deep water column, under the sponsorship of the National science Foundation. PARFLUX Mark II trap, 1978-79 version for PARFLUX phase l program, has been successfully developed and has gathered much meaningful data. A trap opening is $1.5 \mathrm{~m}^{2}$ and consists of 94 hexagonal buffer cells with the nominal form ratio of 2. Sediment particles are concentrated to the receiving cup located at the bottom of the funnel-shaped trap. Two types of receiving cups have been developed; a trap with Type $S$ cup is open at both ends as it sinks to the designated depth. Twenty-four hours after the deployment the receiving cup moves into alignment with the funnel to store the sediment. At the end of deployment a spring mechanism activated by a quartz oscillator based electrical timer-release retracts the receiving cup, seals the collected sample and leave the funnel open at both ends while the trap ascends for recovery. Type $C$ mechanism is installed with a shutter which seals the cup during recovery; this type involves a simple mechanism with less moving parts. Sodium azide/sodium chloride solution is diffused through a series of membrane filters to keep the cup contents in an aseptic condition. Since October 1976 to December 1979, we have deployed and recovered 24 traps successfully along with several moorings as deep as 5,600 $\mathrm{m}$ for as long as 112 days. This reports the engineering detail and Iists the required parts to assist the construction, operation and maintenance of the PARFLUX Mark II sediment trap.
\end{abstract}




\section{Introduction}

The flux of particles through the oceanic water column, its quality and quantity, is important in understanding the processes of marine sedimentation. Indeed, marine flux studies have been receiving attention from many disciplines in recent years (e.g. Wiebe, 1976; Izeki, 1976; Gardner, 1977; soutar et a.1., 1977; Bishop et al., 1978; Honjo, 1978; Spencer et al., 1978; Staresenic, 1978; Knauer et a1., 1979).

Evidence has been found which suggests that there is efficient means of transport of particles, nutrients and man-made matter from the upper layer to the bottom in the pelagic water column (e.g. Osterberg et al., 1963; Schrader, 1971; Honjo, 1976; Elder and Fowler, 1977). Theoretical consideration of ocean particles (e.g. McCave, 1974) has shown that their size distribution may be described as an exponential function. In practice, ocean particles larger than 20 um are rare and have a low probability of occurrence in an open sea water sample (Smayda, 1970; Carder et al., 1971; shelden et al., 1972). However, despite their low abundance, the exponential increase in mass and sinking velocity with size shifts the predominant fraction of mass flux of settling particles to the large size range.

Collection of such large marine particles by ordinary means with water bottle casting is extremely inefficient because of their smaller standing stock and faster sinking rate. Intercepting sinking particles by deploying a receiver has been practiced for a long time in various aquatic environments.

In order to examine the sediment trap samples under diversified multi-disciplinary methods, it is desirable to collect large quantities. This is especially true for radiochemical measurements which often require sediment samples on the order of grams. However, the material flux is usually small in the open sea where the organic productivity is low and is far from the continent. Catchment of a large volume sample can be achieved by a larger aperture and/or longer exposure of a sediment trap. Both of these conditions are severely Iimited in the open sea by the size of traps and logistics of their deployment.

Our basic requirements for designing a sediment trap were: 1) hydrodynamically feasible design for widening the size spectrum of particles to be collected in the slow advective deep ocean layer: 2) ability to collect gram size sediment samples during one deployment; 3) traps must be constructed ruggedly to withstand rough sea conditions, but handled with standard deck equipments of average research vessels; 4 ) the material used should be able to resist corrosion and weakening for at least 18 consecutive months at any depth in the ocean; 
and 5) in our particlar case, metallic contact to the sediment should be avoided. A large, durable sediment trap has thus been developed under the code name of PARFLUX (Particulate Flux) to meet the above requirements under the sponsorship of the Oceanographic Section, National science Foundation. Twelve traps have been manufactured and used to serve for a series of pelagic experiments.

We have deployed the traps along with several moorings at the deep ocean, as deep as 5,600 m deep, using many U.S. research vessels under various sea conditions. They were in water for up to 112 days per deployment. Some traps were redeployed immediately and experienced approximately 12 months of accumulative underwater exposure. We have successfully collected 24 samples from the Atlantic and the Pacific stations. After numerous improvements we are now convinced that a PARFLUX sediment trap is a useful oceanographic research tool. This report outlines the design of a PARFLUX Mark II. More details such as blue plans for each component as indicated in the parts 1 ist of this report can be supplied upon request. The results of scientific research on the collected samples have been published elsewhere (e.g. Honjo, 1978; Spencer et a.1. 1978; Honjo, 1980, in press).

\section{Description of PARFLUX Mark II Sediment Trap}

A PARFLUX Mark II sediment trap consists of three subsystems: 1) collector with honeycomb buffer (Figs. 1, 2, 5 and Plate 1); 2) a receiving cup and a closing mechanism including timer electronics (Figs. 3 and 6 , Plates 2 and 3 ): and 3) a frame to house 1, 2 and buoyancy spheres (Figs. 2 and 5). The air weight of a sediment trap is $872 \mathrm{lb}$. and it is 30 lb. positively buoyant in $18^{\circ} \mathrm{C}$ seawater. Materials used for the construction of the trap were decided based on the results of an exposure experiment in various locations and depths in the deep Atlantic where an assortment of plastics, aluminum alloys and stainless steel were exposed for up to 18 months along a mooring taut line (Plate 4 and partly in Dexter, 1974).

Honeycomb Buffer and Funnel

The buffer has a $145 \mathrm{~cm}$ diameter opening and consists of 94 maximum packed hexagonal cells totalling 1.5 square meters (Fig. 1) and are made of $1 / 6^{\prime \prime}$ thick polyvinyl chloride (PVC) Trovidour ${ }^{R}$ sheet. Hexagonal cells are made by fitting PVC sheets which are bent in alternation of $120^{\circ}, 180^{\circ}, 240^{\circ}$ and $180^{\circ}$ (refer to Honjo's internal memorandum, April 29, 1976 . 


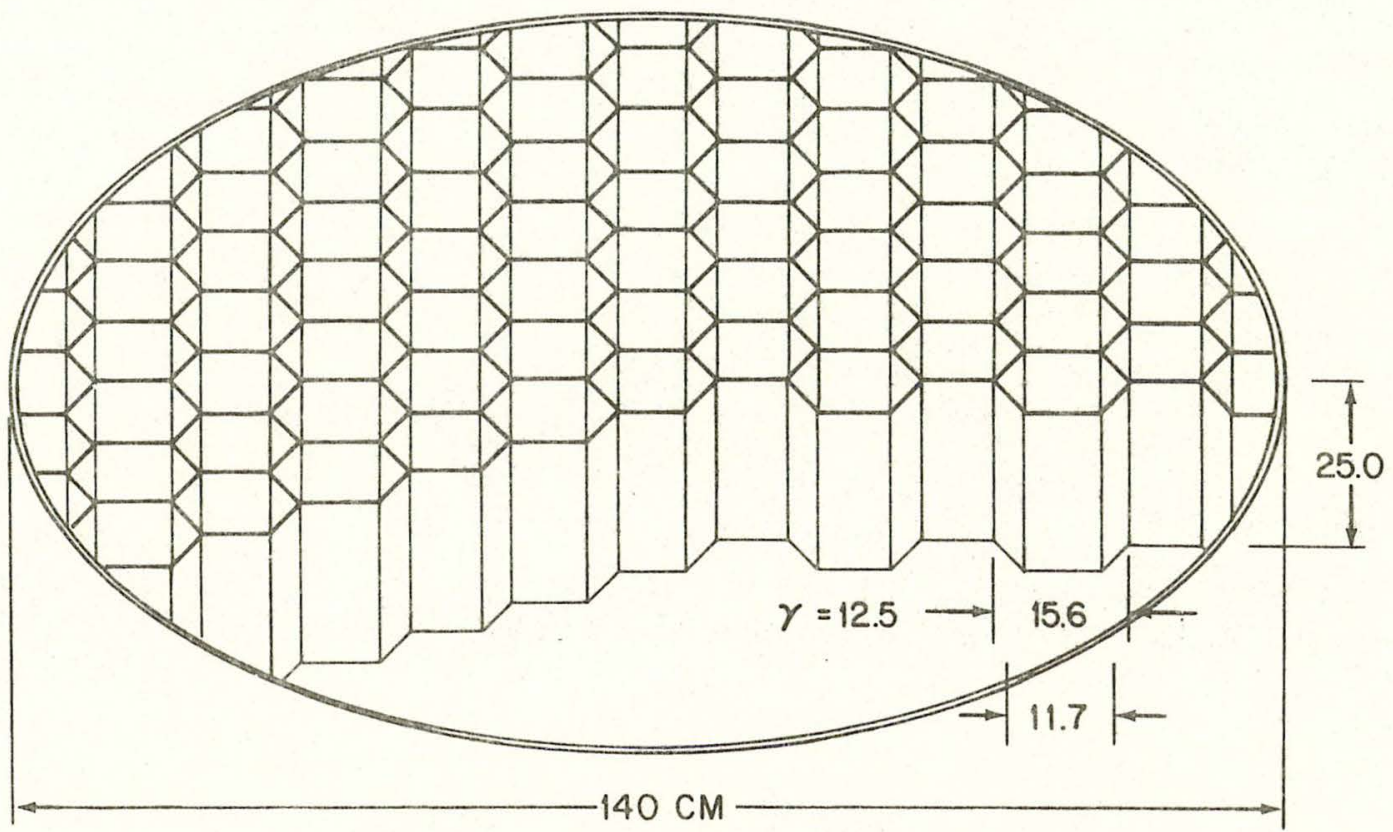

Fig. 1. Configuration of a buffer and hexagonal cells.

The buffer alternates the horizontal element of flow and corrects the trajectory of travelling particles toward the direction of gravity. Soutar et al. (1977) reported that the steady horizontal flow is inhibited at the depth equivalent to $20 \%$ of the width of a buffer cell when the form ratio of cells (diameter vs. depth of a cell) is sufficiently large.

The diameter of the circumscribed circle of a hexagon was $15.6 \mathrm{~cm}(11.7 \mathrm{~cm}$ for inscribed circle) (Fig. 1). The height of a cell. was $25 \mathrm{~cm}$ (nominal form ratio: 2.0). The outer ealge of a collector is tapered at 21 degrees in order to fit in the upper margin of the funnel.

The diameter of the upper opening (ID), lower opening (ID) of a collecting funnel were $146 \mathrm{~cm}$ and $10 \mathrm{~cm}$, respectively. The height was $178 \mathrm{~cm}$ forming $42^{\circ}$ frustrum angle. We used Trevodour ${ }^{\mathrm{R}}$ linear PVC for funnel construction. A Eunnel shape was cut from $1.0 \mathrm{~cm}$ thick, $8^{\prime} \times 8^{\circ}$ polyvinyl chloride sheet stock and formed over a steel mold in a $120^{\circ} \mathrm{C}$ oven. The seams were then hot air welded. The upper and lower edges were cut and ground flat to accept the mounting plate. Then the funnel was annealed for a few days at $60^{\circ} \mathrm{C}$. The seam that appears on the interior surface of a funnel was ground smooth and lapped by fine buffing. A sample of the buffed surface was checked under SEM for smoothness (Plate 4). Four channels made of $2 \mathrm{~cm}$ thick PVC were attached to the frustrum to mount the funnel assemblage to the Erame via U-shaped tubings. A square plate to accept the receiving cup mechanism was welded to the bottom of the funnel and the lower end of the channels (Figs. 2 and 5 ). 
Receiving Cup Mechanism

Two types of receiving cups have been developed for the PARFLUX Phase 1 experiment. Type $C$ (a shutter insulates the receiving cup) was first developed mainly by Mr. Connell and successfully used during many of the Phase 1 experiments. Dr. W. Deuser developed the moving cup mechanism for his experiments (Deuser and Ross, in press) applying the PARFLUX trap. Mr. P. Sachs, assisted by Mr. D. LeBlanc, completed the engineering of the Type s mechanism which is now used as the standard PARFLUX instrumentation.

We are intending to use the Type s receiving cup mechanism for further deployments. However, Type $C$ is still useful for certain applications: for example, a short deployment which the timing error caused by the duration corrodible ring äissolution is significant.

Type S Receiving Cup (Fig. 3). The receiving cup mechanism advances three sequences automatically. The funnel is open while a trap descends to the designed depth (open mode). After 24 hours the receiving cup is aligned to the lower opening of the funnel and starts to collect sediment (recieving mode). Before retrieval, the cup closed sealing the accumulated sample and reopening the lower end of the funnel (holding mode).

The favorable characteristics of the PARFLUX $S$ type receiving cup design are: I) The trap is deployed with the lower end of the funnel being open which results in the immediate flooding of water after launching, leaving less chance of being disturbed by surface waves; 2) The funnel. assemblies can be flushed thoroughly by sea water while sinking through the water with a descending speed of approximately 65 $\mathrm{m} / \mathrm{min}$. This eliminates the chance of contamination of sample from the surface water: 3) The receiving cup can retain a saline solution with concentrated sodium azide. When the cup slides to the receiving mode, heavier solution stays in the receiving cup and the first arriving particles to the cup are readily sterilized. Thus the sediment maintains an aspetic condition throughout the deployment; 4) When the cup is retracted to the holding mode, no water from the sample can leak out from the cup due to the tight seal. The trap can be retrieved on the deck in any position; and 5) the cup assembly can be attached or detached in a matter of seconds.

The mounting plate (a in Fig. 3 ) is $3 / 4$ " thick PVC, $10 "$ wide, $18^{\prime \prime}$ (for $S$ type, $12^{\prime \prime}$ for $C$ type) long and welded to the bottom opening and the lower ends of the anchoring channel (Fig. 1). The cup assembly (b through g in Fig. 3) is housed in the glider plate (b), and it is attached to the mounting plate by 6 heavy duty buckles (c). Neoprene sheet (1/32" thick) is sandwiched between those two plates. The receiving cup (d) is made of clear $6^{*}$ diameter, $6^{\text {" high Lucite }}$ 
Fig. 2. An illustration of a PARFLUX Mark II sediment trap with an 5 type receiving cup. a: trap opening where a buffer (Eig. I) is installed; b: a funnel; c: frame; d: flotation spheres (only hard hat covers are shown); e: "moving cup" mechanism; E: a pressure case for timer electronics and batteries; g: a receiving cup; h: bacteriacides diffusion chamber; $i$ and $j$ : spring to move and retain g; k: titanium burnwire. Magnesium corrodible Iink ( $n$ ) is now released. Bridles (p) fasten a trap to the mooring line through $0-r i n g s(0)$. 


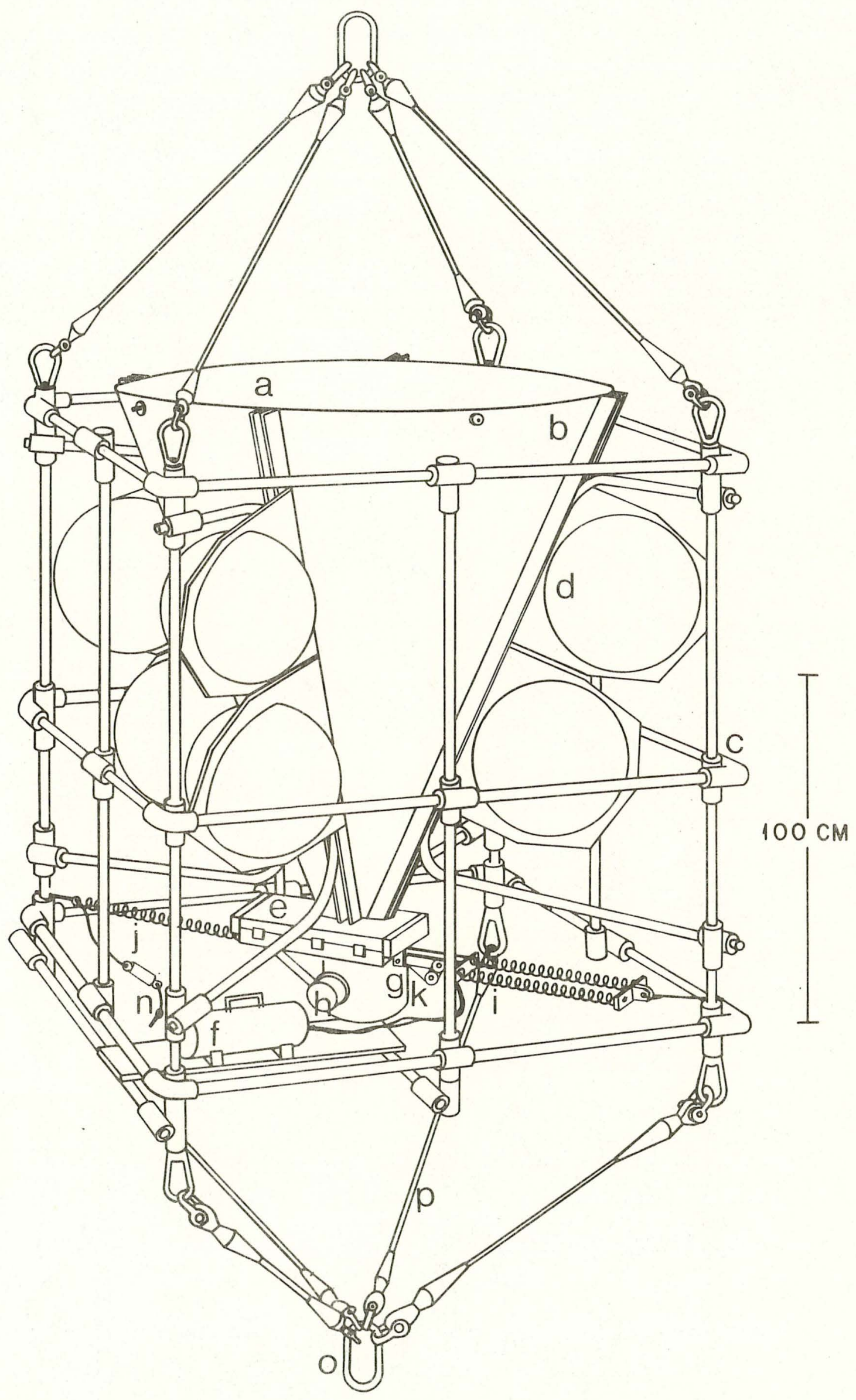


cylinder with $1 / 4$ " thick wall. The receiving cup retaining plate (e) was milled from 1/2" LuciteR sheet stock and glued to the cylinder with a "tongue and groove" configuration. A Teflon $R$ coatd, Quad- $x^{R}$ sealing $r i n g$, Neoprene ${ }^{R}$, is installed in the groove on the upper surface of the plate $(\mathrm{g})$. The grease retaining groove on the sealing-ring should be filled with non-water assimilating silicon lubricant such as General Electric ${ }^{\mathrm{R}}$ SC-206.

The cup assembly slides open and shut along the guide rail (h) with a two stage retraction of a pair of springs with different tension strengths ( $i$ and $j)$. These springs are attached to the cup retaining plate (e) via mounting hardwares (k) and the other ends are anchored to the vertical tubing of the frame in a diagonal fashion. First, the weaker spring (i) is fastened in a retracted position with a retaining wire (I) which holds the cup in a recessed position during the open mode. The length of the wire can be adjusted by a turn-buckle (m). A magnesium corrodible link ( $n$ ) dissolves in approximately 24 hours ( \pm 3 hours) in the seawater. Then the cup assembly is pulled by a double spring ( $j$ ) and stopped by an end-plate (p) at the position where the holes on b and $e$ align with the bottom opening of the funnel to accomplish the receiving mode. When the burn-wire $(q)$ is fused by a signal from the timer electronics, the receiving cup is released from the pull of a double spring ( $j$ ) via multiplying lever $(r)$ and it is retracted again to the recessed position by the weak spring (i).

The tension strengths of the double spring ( $j$ ) and weak spring (i) are approximately $45 \mathrm{lb}$. and $30 \mathrm{lb}$. respectively. A lever $(r)$ reduces the pull of the double spring ( $j$ ) on burnwire (q) by 7.5 times. A typical arrangement for the spring tension usually practiced is illustrated in Fig. 4. The burnwire is stretched between two pulleys (s) with less than 7 lb. protecting the junction of titanium wire from metallic fatigue during a long deployment. At this retracted position (hold mode), the cup is sealed against the polished lower surface of the glider plate (b) via Quad- $\mathbb{X}^{R}$ seal (f). Five studball bearings ( $t$ ) are installed on the guide channel ( $h$ ) for smooth reciprocation of the receiving cup. The weak spring should retain 15 1b. of retention strength during the holding mode. We used $25 \mathrm{~cm}$ long $141 / 2^{\prime \prime}$ (ID) tight coiled, type 316 stainless springs. 


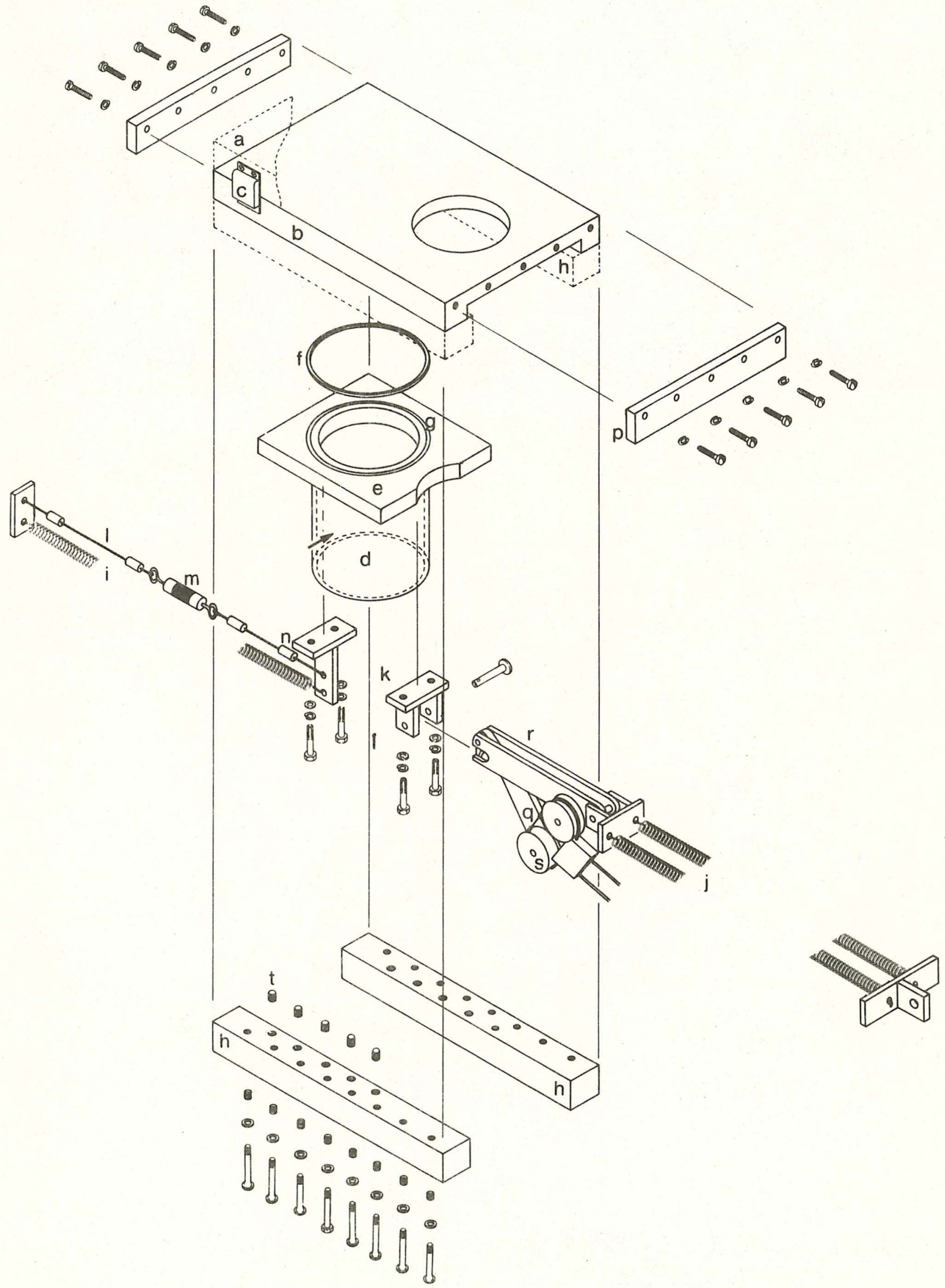

Fig. 3. Assemblade schematice $n f$ on $c$ t.......... 


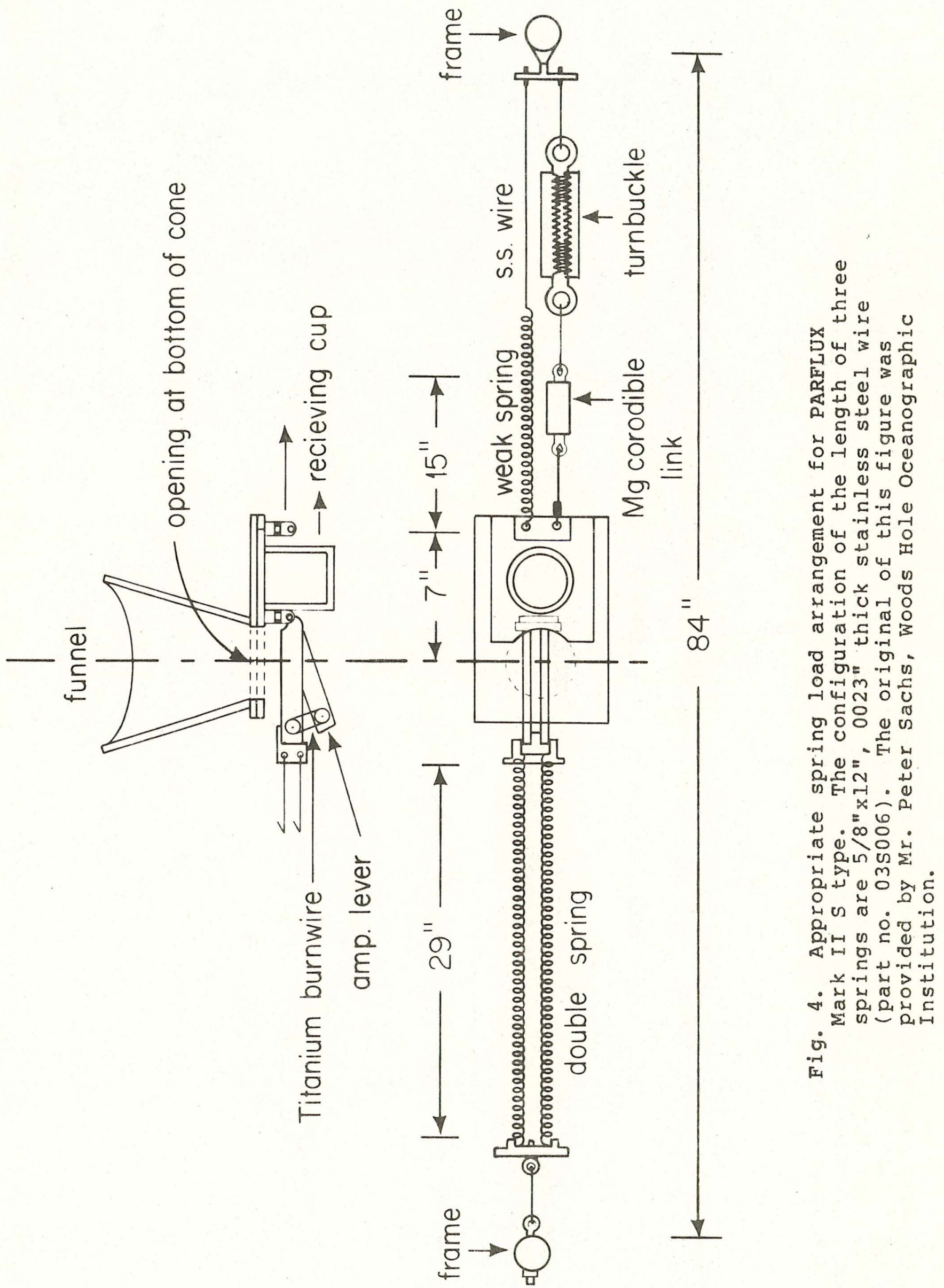


Type C Receiving Cup (Fig. 6). Type C receiving cup mechanism involves one movement of relatively light weight shutter made of Devlin ${ }^{R}$. A trap is deployed with the receiving cup open. Water emerges from the gaps between the face plate and shutter and it takes over ten minutes before a trap submerges. When the burnwire is cut by the signal from the timer release, common as Type $\mathrm{S}$, the shutter closes the receiving cup and the contents are tightly sealed by retention springs (Fig. 6i) and sliders (K) which push the shutter (e). An advantage of a Type C mechanism is that this is much simpler than a Type $\mathrm{S}$ involving less moving parts and less adjustment is required.

The mounting plate (a) is $3 / 4 "$ thick PVC, $10 " \times 10 "$, and welded to the bottom opening and lower ends of the anchoring channel (Fig. 5). The cup assembly is attached to the facer plate (b) by eight ( 8 ) sets of tension springs (u), washers and machine bolts (w). The dimension of the receiving cup is the same as in Type S (Fig. 3). A TeflonR coated, NeopreneR, Quard- $x^{R}$ sealing ring (f) is installed in the groove on the upper surface of plate $(\mathrm{g})$. The grease retainer groove on the sealing-ring should be filled with non-water assimilating silicon lubricant such as General ElectricR SC-206.

A shutter (e), 1/2"x6"x18" Delrin sheet, is sandwiched between the facer plate (b) and sealing ring (f) via sliders (k) with compressor springs $(j)$. The hole on the shutter should be aligned through the holes on the mounting plate, cup opening and the bottom of the funnell. This can be adjusted by the turnbuckle (m) after installing the burnwire ( $q$ ) via two blocks (s) and loose joint ( $n$ ) with a pin (h). While assembling the receiving cup mechanism, sliders (k) with compressor springs ( $j$ ) tend to drop from the retaining grooves on the facer plate (b) (indicated by broken lines); therefore, it is recommended to fastern them temporarily by a pair of set screws ( 1 ).

The length of tension spring should be adjusted from 12 " to $101 / 2$ " depending upon the fixture which holds the spring at the far end. The standard tension of the shutter is 17 lb. during the receiving mode; 6 lb. of retaining tension is necessary to hold the shutter at the closed position. Slider and lower surface of the shutter should be lubricated by applying the thin but consistent film of $\mathrm{GE}^{\mathrm{R}} \mathrm{SC}-206$ compound. 


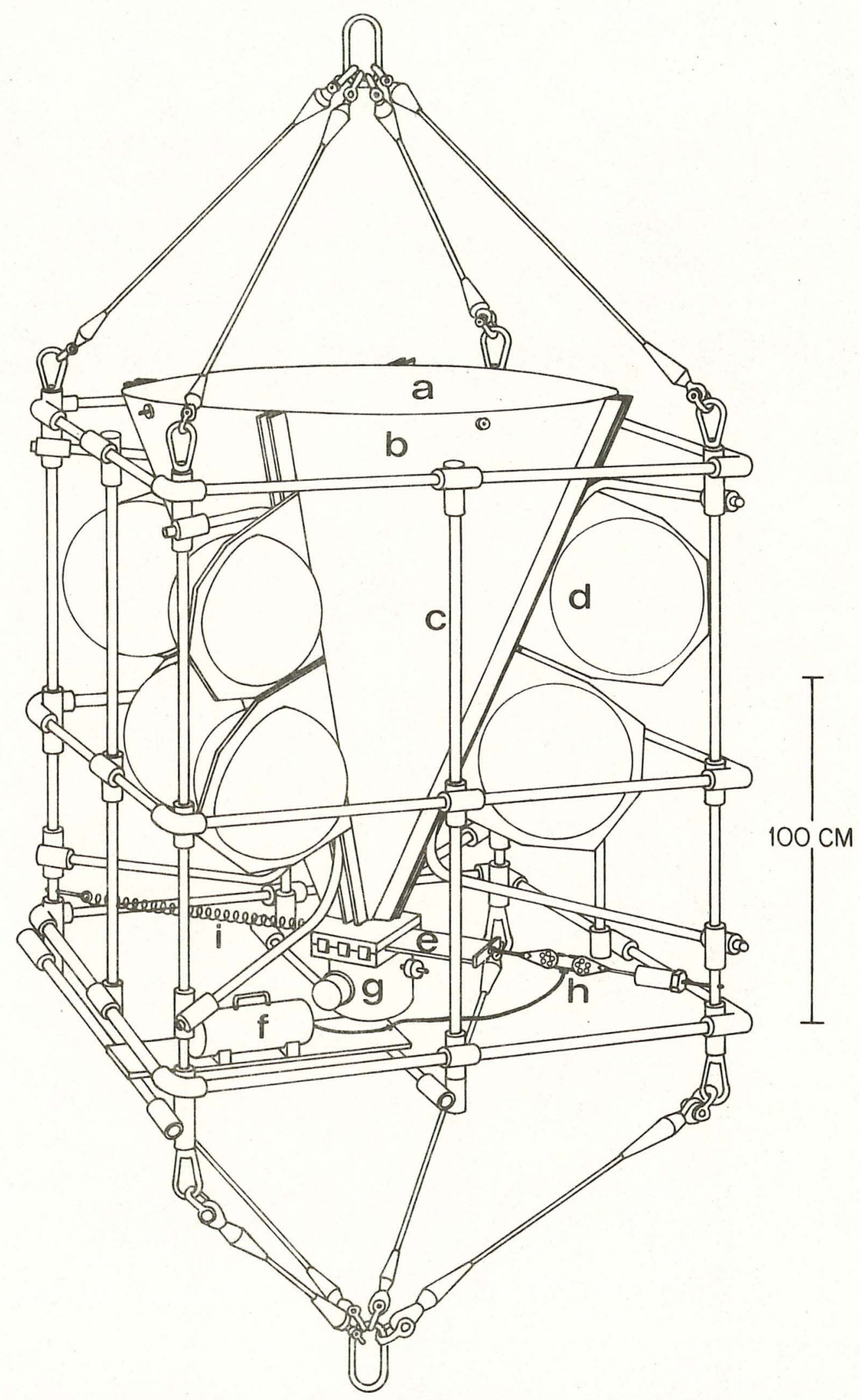

Fig. 5. An illustration of a PARFLUX Mark II sediment trap with a $c$ type receiving cup. a to $d$ is the same as in Fig. 2. E: shutter plate, h: burnwire, $i$, single spring to shut and retain $e$. 


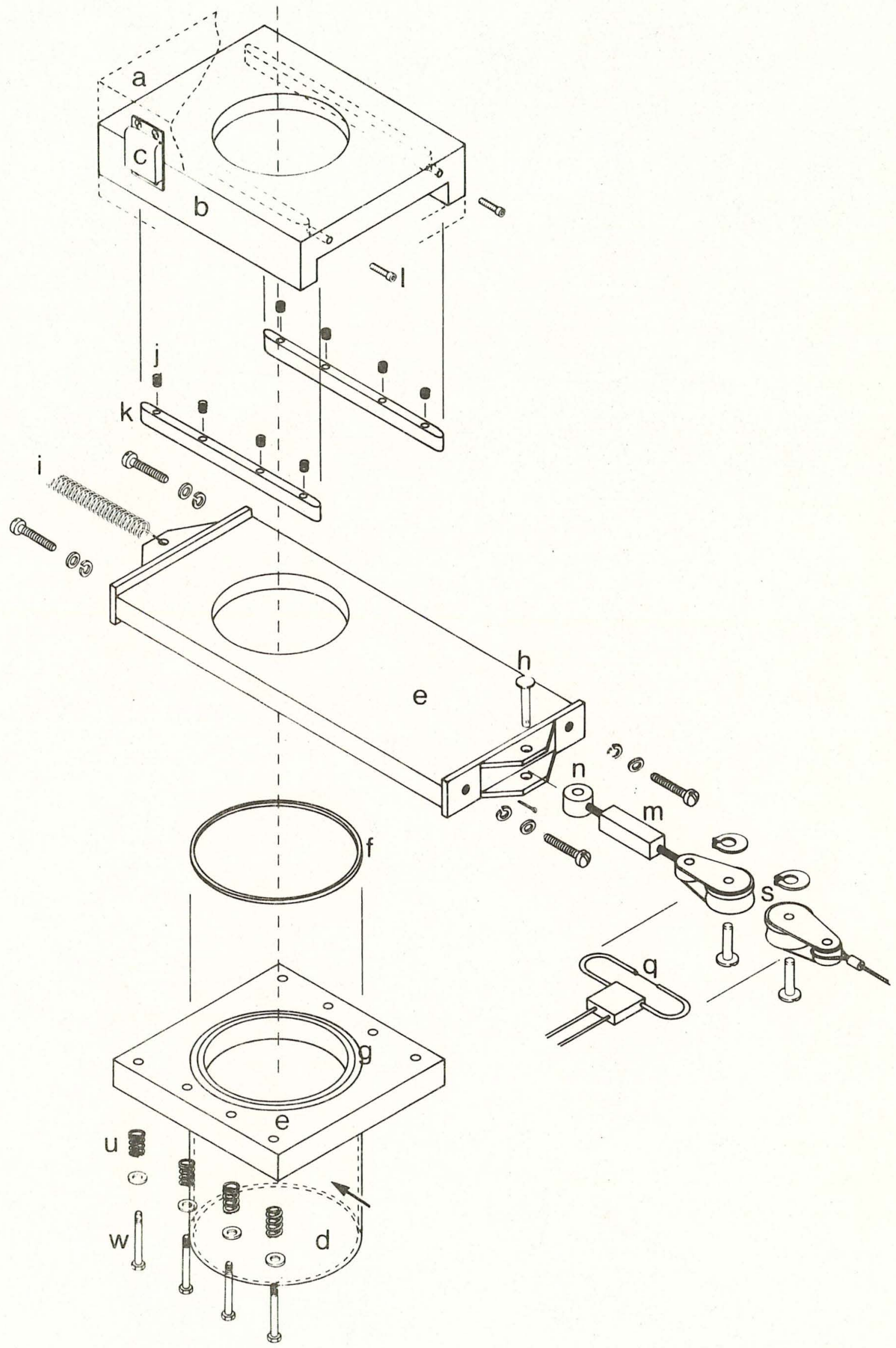

Fig. 6. Assemblage schematics of a $c$ type receiving cup.
Refer to text. 


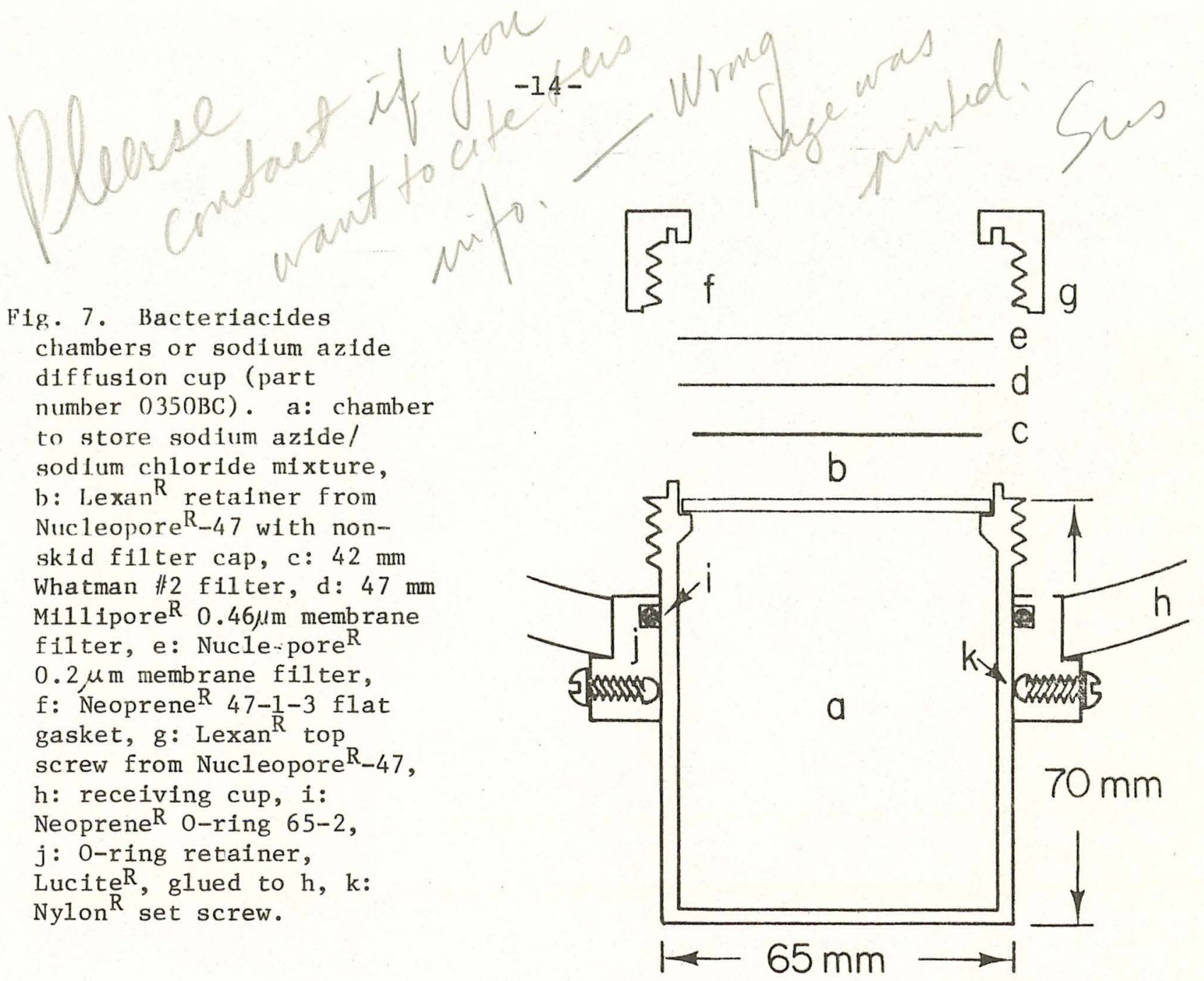

Bacteriacides chamber. Bacteriacide chambers are $6.5 \mathrm{~cm}$ in diameter (OD), $7 \mathrm{~cm}$ high, and $3 \mathrm{~mm}$ wall thickness (Lucite cylinder). One end is closed and the other was fitted with a commercially available $45 \mathrm{~mm}$ membrane Eilter retainer

(Fig. 7). The lower half of the cylinder is packed by sodium azide (refer to Appendix 1) and sodium chloride at a ratio of 4 to l. in weight. The rest is filled with a mixture of the same material but in reversed ratio. It requires 60 grams of sodium azide. The open-end of the cylinder is covered with a lamination of filters; from bottom to top $4.25 \mathrm{~cm}$ diameter Whatman \#l filter, $47 \mathrm{~mm}$ Millipore filter with the nominal perforation of $0.2 \mu \mathrm{m}$. The lamination is mounted to the container by a threaded adaptor with a silicon rubber gasket. The container was then placed through a hole in the side of the recieving cup (for mounting refer to Figs. 2 and 5 , also location indicated by an arrow mark in Figs. $3 d$ and $6 d$ ) through an O-ring and anchoring Nylon ${ }^{R}$ bolts. The filter side of the cylinder is exposed to the inside of the chamber.

Special Caution in handling sodium azide is explained in the Appendix of this report. 
Electronic Timer (refer Appendix 2 for details)

The electronic timer (Fig. $2 f$ and Fig. $5 f$ ) is a quartz oscillator clock device developed by Benthos ${ }^{R}$ Inc. The electronics and batteries are housed in a $41 / 2$ "diameter (OD), 1.0" long stainless steel pressure housing. The time duration can be adjusted from one hour to 9,999 hours in one hour increments. The circuit can be tested by a fast run mode converting hours to seconds. The timing error at room temperature is less than 60 minutes for 12 months of deployment. We also have successfully used WHOI-Williams electronic timers.

The burnwire is a 10 " long, number 16 titanium wire that is formed into a loop by electron beam welding at the ends. The loop is hot-coated by $1 \mathrm{~mm}$ thick Neoprene insulation leaving a $1.5 \mathrm{~mm}$ slit where the titanium wire is exposed. A submersible electric cable from the battery via relay is connected to the loop. Timer signal is relayed to two independent sets of burnwire current supplies in order to be fail-safe. Recommended voltage is 64 volts DC or more. Tension strength (momentary) of an insulated loop is $125 \mathrm{lb}$. in a laboratory test. It takes approximately 30 seconds to corrode a burnwire at $2^{\circ} \mathrm{C}$ under $10 \mathrm{lb}$. of tension at ambient pressure supplying $64 \mathrm{~V}$ DC. The burnwire for an OSI-Williams timer is made of number 18 stainless steel wire. Specification is available in Williams" internal memorandum, issue to "list" in July 1976.

Frame

The dimension of a frame is $183 \mathrm{~cm}$ high (excluding eyebolts), $162 \times 162 \mathrm{~cm}$ deep square at the base and is made of 1 $1 / 2$ " schedule 40, marine grade, class 6001 aluminum tubing. All the corners and cross-bars were furnished with marine grade aluminum fittings (Figs. 2 and 5). A trap requires a total of $48.8 \mathrm{~m}$ of tubings and 37 matching fittings ( 25 "T"s and 12 corners). A threaded rod of 1" diameter is inserted through four vertical tubings via Telfon ${ }^{R}$ snug-fit bushings. 2" eyebolts and $2^{\prime \prime}$ shackles were attached to both ends of a rod to accept the bridles made of $3 / 8$ " vinyl coated steel wire. The tensile strength between both ends of bridles are tested to 5 tons.

Four 2" aluminium tubes are bent 24 and 62 degrees to form a deviated U-shape and mounted diagonally to the four vertical tubes (Figs. 2 and 5). A $1 / 8$ " thick Neoprene ${ }^{R}$ sheet is padded throughout the inside of the anchoring channels along the frustrum. The funnel is fastened with $3 / 8$ " stainless steel bolts through I" diameter Neoprene ${ }^{R}$ shock absorbing bushings. 
It has been found that the deployment/recovery is eased significantly by providing each sediment trap with sightly positive buoyancy ( $30 \mathrm{lb}$.) which is enough to resist sinking by the weight of the adjacent wire shots. This much buoyancy does not sacrifice the stability of the trap while being deployed. We have installed eight $17^{\prime \prime}$ diameter, Benthos ${ }^{R}$, PyrexR buoyancy spheres covered by $A B S$ resin hard hats. Two spheres are mounted on a U-shaped tube by $3 / 8^{\prime \prime}$ stainless steel bolts via Teflon $R$ insulation tubes.

Prevention of Corrosion

All the contacts between stainless steel and aluminum are insulated with nylon bushings and washers. All the threaded surfaces are coated with Teflon ${ }^{R}$ sealing paste. Four $1 / 21$. zinc anodes are mounted on the lower part of the frame. A smaller anode $(1 / 16$ 1b.) is also mounted on the pressure case which houses electronic timers.

During the last 50 months, PARFLUX traps have been deployed up to 12 months in water. On many occasions, some traps were stored in near-shore open storage for several months. In one case they were on-board outside for a few months while a ship cruised in the tropical areas. Despite those adverse conditions, the PARFLUX sediment traps have not undergone significant wear and corrosion. The surface quality of PVC was checked frequently under the SEM using test pieces deployed with the traps: no significant change in surface smoothness was found. Plate 4 illustrates comparison of the PVC

(TrovidourR) 6001 aluminum and 360 stainless steel before and after the three subsequent deployments totalling 283 days at the bathypelagic depth.

A trap should be thoroughly rinsed by fresh water immediately after recovery and before land storage. Also, the trap should be washed thoroughly with a mild detergent mixed in $50^{\circ} \mathrm{C}$ water before deployment.

\section{Mooring Array}

We used $3 / 16^{\prime \prime}$ steel tautline with polyethylene coating. The tensile strength of the line is tested to 2.5 tons. Thirty meters of 3/4" nylon shots are deployed above and below a trap.

As shown in Fig. 8, the sediment traps were deployed in various depths from $400 \mathrm{~m}$ to $5,685 \mathrm{~m}$. In order to minimize the swiveling motion of the mooring and to keep the opening as horizontal as possible, the mooring line tension above the traps was kept at 1,300 1b. to 1,500 1b. A model calculation of the Equatorial Atlantic array in Fig. 8 indicates that the 
possible tilt from vertical at $5,068 \mathrm{~m}, 3,755 \mathrm{~m}, 988 \mathrm{~m}$ and 377 $\mathrm{m}$ is $120,10^{\circ}, 70$ and 40 respectively under

hypothetical uniform advection of $30 \mathrm{~cm} / \mathrm{sec}$. Considering surface current shear and animal attacks, it appears that approximately $400 \mathrm{~m}$ is the shallowest a sediment trap can be deployed with satisfactory performance. On the other hand, pressure resistance of instrument pressure cases is the only limiting factor for the deepest deployment.

Since the reliability of our acoustic releases has been very high if proper preparation is maintained (99.9\% of recovery rate by the Moored Array Management, Woods Hole Oceanographic Institution), we used a single release throughout the experiment except for the $\mathrm{P}_{1}$ array which had a tandem release. The details of the PARFLUX mooring design and its performance will be reported elsewhere (Clay and Honjo, in prep.). 


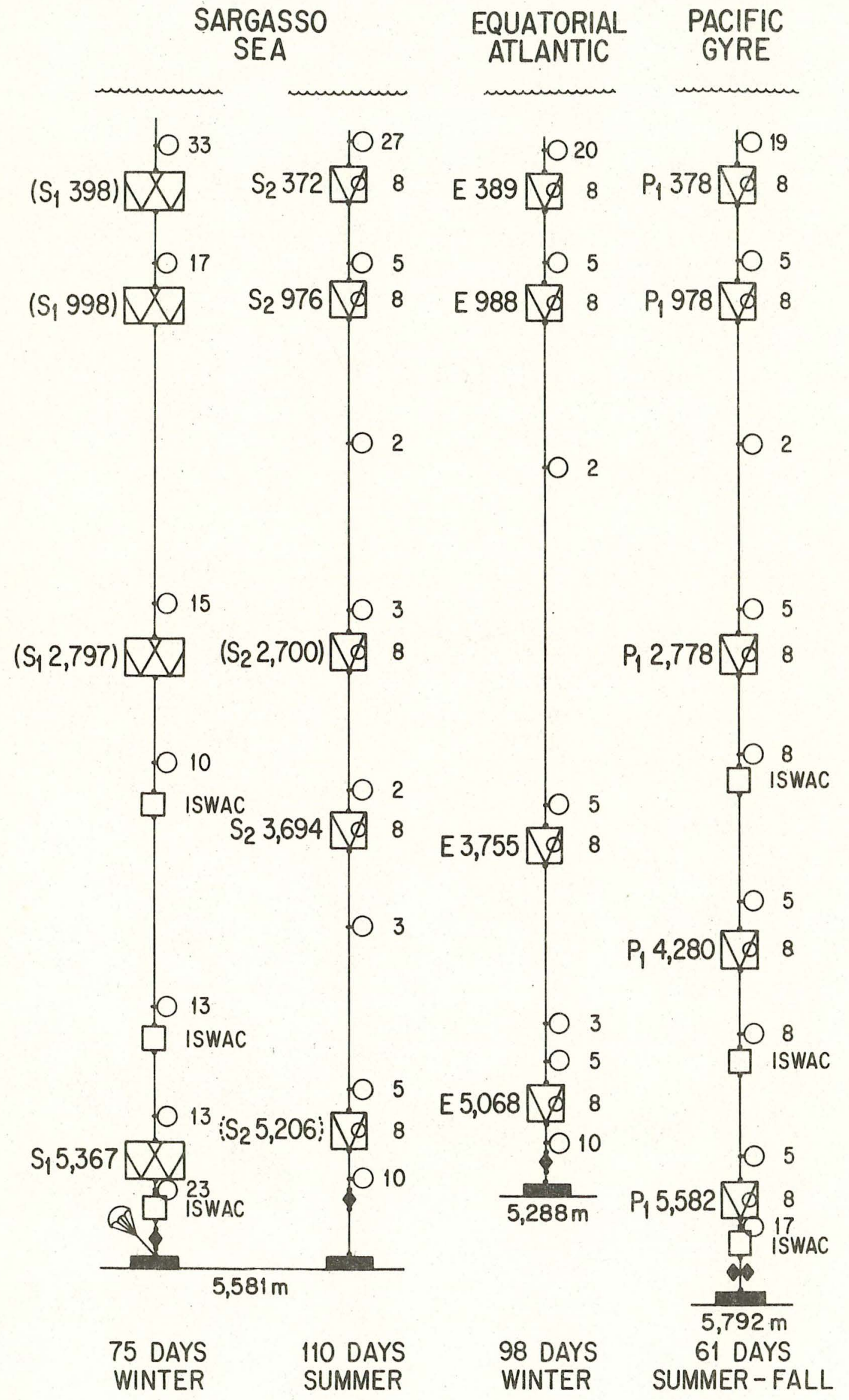


Result and Discussion

The benefit of a large opening of the PARFLUX Mark II trap well cancels out some of the inevitable disadvantages of being large and heavy. For example, the bathypelagic sargasso sea is presumed to be one of the most barren waters in terms of the flux of sediment because of its low productivity and distance from land; we have collected approximately 1.5 to 2 grams of sample during 110 days of deployment, which proved sufficient to carry on multi-disciplinary research including

radiochemistry (Honjo, 1978; Spencer et al., 1978). Table I shows the volume of sediment collected in the traps and calculated flux so far deployed in the open sea (Honjo, in press). The recent Panama Basin experiment (PARFLUX $P_{2}$ ) collected up to 50 grams of pelagic sediment during 112 days of deployment.

Gardner (1978) measured the trap's efficiency ( $\%$ of vertical flux) by different shapes in slow advection of flume water equivalent to several centimeters per second in the laboratory. Such current velocity was typical in the mesopelagic and bathypelagic water of the large open sea (i.e. Schmitz, 1978, 1979). Gardner (1978) observed that 1) the collecting efficiency of a trap of fine grained oceanic sediment particles ( $95 \%$ were smaller than $25 \mu \mathrm{m}$ ) is a function of the residence time and flow pattern of fluid within the trap at a given velocity, 2) the flow pattern is decided by the geometry of the sediment trap, and 3) the particles of the size range above mentioned are collected through a process of fluid exchange rather than falling freely into a trap. The same paper reported that a shallow funnel whose opening is parallel to the flow direction generates an upwelling along the far-side slope of a funnel which tends to cause undertrapping of particles. His scaled-down model of the sedient trap using a funnel and buffer, somewhat similar to a PARFLUX Mark II, showed 65 to $90 \%$ of trap efficiencies at $5 \mathrm{~cm} / \mathrm{sec}$ advection. The funnel angle of our trap was much steeper than the funnel he used in his experiment; $450 \mathrm{vs}$. 120, resulting in the fluid residence time in our trap being significantly longer than in Gardner's experiment. However, there has been evidence that such laboratory results would be applicable to the field.

since the $230 \mathrm{Th}$ concentration in sea water is negligible compared to that of $234 \mathrm{U}$, one can assume that the production rate of $230 \mathrm{Th}$ by the decay of $234 \mathrm{U}$ in the water column above the trap is equal to the vertical flux of $230 \mathrm{Th}$ at the depth of the trap deployed (spencer et al., 1978). Thus by comparing the measured $230 \mathrm{Th}$ flux with the calculated production rate of $230 \mathrm{Th}$, a trapping efficiency may be calculated. Brewer et al. (in press) estimated trapping efficiencies for particles on $230 \mathrm{Th} 70,78,78$ and $67 \%$ for 
$398 \mathrm{~m}, 988 \mathrm{~m}, 3755 \mathrm{~m}$ and $5086 \mathrm{~m}$ traps deployed at the PARFLUX $\mathrm{E}$ site, in the Equatorial Atlantic. Deep current velocity in this area is believed to be equivalent to the other two experimental sites (Honjo, 1980, in press).

Realistic concentration of sodium azide in the receiving cup while the trap is being deployed is not known. A tank experiment with still seawater under ambient temperatures demonstrated that the salinity of the water inside of the cup increases continuously up to 15 days and maintains the higher salinity for at least 9 weeks up to the opening of the receiving cup (unpublished). It is assumed that sodium azide remained with heavier saline water in the cup and this aseptic environment is provided for possibly as long as several months under bathypelagic conditions. In about $20 \%$ of the traps deployed so far there remained a few grams of sodium azide in the bacteriacides chamber. Assuming that sodium azide diffused in like manner, a rough estimate of the rate of diffusion is $300 \mathrm{mg} /$ day average. The volume of the receiving cup (including the thickness of the face plate) is approximately 3 liters and the estimated exchange rate is approximately $100 \mathrm{ppm} / \mathrm{day}$. The bacteria over the fecal pellets (Honjo and Roman, 1978; Turner, 1979 ) were not recognized under SEM in any samples even from $400 \mathrm{~m}$ traps. No trace of bacterial growth was recognized in a poisoned cup (Sargasso sea sample from $5,356 \mathrm{~m}$ ) after being stored in $2^{\circ} \mathrm{C}$ and $10^{\circ} \mathrm{C}$ for 10 months after recovery. systematics change of organic carbon and nitrogen contents were not recognized after several months the samples were kept in cold storage in the original poisoned water recovered with a receiving cup for at least 10 months. 


\section{Acknowledgements}

We thank Dr. D. Spencer and Dr. P. Brewer for their helpful discussions. Mr. P. Sachs contributed a great deal to the project especially by designing the receiving cup which was described in this report. Technical advice from Mr. D. LeBlanc and Mr. R. Walden has been very useful. Dr. J. Erez has cooperated in all phases of the development of the PARFLUX experiment. Dr. W. Deuser's suggestion for the mooring cup mechanism was adjusted to our design.

We owe many thanks to Dr. W. Schmitz, Mr. K. Bradley, Mr. P. Clay, Mr. P. O'Malley, Mr. R. LaRochelle, and Mr. D. Simoneau for their support and cooperation during the experiments. The data used in Table 1 was obtained with the able assistance of Mr. S. Manganini. Dr. J. Milliman and Mr. $K$. Doherty reviewed this report and their criticisms have been very valuable. The administration of the PARFLUX Phase 1 program was assisted by Mrs. S. Pelletier.

Special thanks are due to Dr. Kazuyoshi Sato who has provided valuable information and advice about microbiology and associated environmental problems concerning the use of sodium azide.

This research was supported by the generous funding provided us by the Oceanography section of the National science Foundation under Grants OCE76-10514 and OCE76-82063. 


\section{REFERENCES}

BISHOP, J.K.B., J.M. EDMOND, D.R. KETTEN, M.P. BACON and W.B. SILKER (1977) The chemistry, biology and vertical flux of particulate matter from the upper $400 \mathrm{~m}$ of the equatorial Atlantic Ocean. Deep-Sea Research, 24, 511-548.

CARDER, K.L., G.R. BEARDSLEY and H. PAK (1971) Particle size distribution in the Eastern Equatorial Pacific. Jour. Geophys. Res., 24, 5070-5079.

DEXTER, S.C. (1974) Microbiological faulting and its control in coastal water and the deep ocean. Woods Hole Oceanographic Institution Technical Report, 74-64, 48 pp.

ELDER, D. and S.W. FOWLER (1970) Polychlorinated byphenyls: penetration into the deep ocean by zooplankton fecal pellet transport. Science, 197, 459-46I.

GARDNER, W.D. (1977) Fluxes, dynamics and chemistry of particulates in the ocean. Ph.D. Thesis, Massachusetts Institute of Technology/Woods Hole Oceanographic Institution Joint program in Oceanography

HONJO, S. (1976) Coccoliths: production, transportation and sedimentation. Marine Micropaleontology, 1, 65-79.

HONJO, S. (1978) Sedimentation of materials in the sargasso sea at a $5,367 \mathrm{~m}$ deep station. Journal of Marine Research, 36 , $469-492$.

HONJO, S. (1979) Material fluxes and modes of sedimentation in the mesopelagic and bathypelagic zones. Submitted to Journal of Marine Research, July 1979.

HONJO, S. and M.R. ROMAN (1978) Marine copepod fecal pellets: production, preservation and sedimentation. Journal of Marine Research, 36, 45-57.

IZERI, S. (1976) Vertical transport mechanism of particulate organic matter in the open sea. Ph. D. Dissertation, Hokkaido University, 138 pp., abstract in IZEKI, R. (1976) Vertical flux of particulates by a floating collector. Kaiyo Nagaku Noto, $3,18-25$.

KNAUER, G.A., J.H. MARTIN, and K.W. BRULAND (1979) Fluxes of particulate carbon, nitrogen and phosphorous in the upper water column of the Northeast Pacific. Deep Sea Research, 26. $97-108$.

MCCAVE, I.N. (1975) Vertical flux of particles in the ocean. Deep-Sea Research, 22, 491-502. 
OSTERBERG, C., A.G. CAREY and H. CURL (1963) Acceleration of sinking rates of radionucleides in the ocean. Nature, 200, $1276-1277$.

SCHMITZ, W.J., JR. (1977) On the deep general circulation in the Western North Atlantic. Jour. Mar. Res., 35, 21-28.

SCHMITZ, W.J., JR. (1978) Observation of the vertical distribution of low frequency kinetic energy in the western North Atlantic. Jour. Mar. Res., 36, 295-310.

SCHRADER, H.J. (1971) Fecal pellets: Role in sedimentation of pelagic diatoms. Science, 174, 55-57.

SHELDON, R.W., A. PRAKASH and W.H. SUTCLIFFE (1972) The size distribution of particles in the ocean. Limnol. Oceanogr.., 17: $327-335$.

SMAYDA, T.J. (1970) The suspension and sinking of phytoplankton in the sea. Oceanogr. Marine Biology Annual Review, 8 , $353-414$.

SOUTAR, A., S.A. KLING, A. CRILL, E. DUFFRIN and K.W. BRULAND (1977) Monitoring the marine evironment through sedimentation. Nature, 266, 136-139.

SPENCER, D.W., P.G. BREWER, A. FLEER, S. HONJO, S. KRISHNASWAMI, AND Y. NOZARI (1978) Chemical fluxes from a sediment trap experiment in the deep Sargasso Sea. Jour. Mar. Res., 36(3), 493-523.

STARESENIC, N. (1978) The vertical flux of particulate organic matter in Peru Coastal current. Ph.D. Dissertation, Massachusetts Institute of Technology/Woods Hole Oceanographic Institution Joint Program in Oceanography.

TURNER, J.T. (1979) Microbial attachment to copepod fecal pellets and its possible ecological significance. Trans. Amer. Microsc. Soc., 98, 131-135. 


\section{PARTS LIST}

Parts necessary to construct a PARFLUX Mark II are listed in the following section. Type $S$ and $C$ receiving mechanisms differ significantly. Therefore, the respective parts lists were separately prepared.

02: Collector subsystem

03C and 03S: Receiving cup subsystem

04: Timer electronics subsystem

01: Framework subsystem

10: Mooring array (not included)

Assemblage position of those parts can be referred to the illustrations in Figs. I through 7. The list should be read in the following order:

1. PARFLUX parts number

2. Name of the parts

3. Material to be used

4. Description, specification for order

5. Number of part required to construct a trap

6. Number of optimal spare part to be brought to a deployment cruise.

7. Price per piece if supplied from inventory. Unless specified, published price is as of November 1, 1979.

8. Distributor, supplier or manufacturer. Valid only for the northeastern coastal united states.

9. Order item ( 0 ), stock item ( $s)$, blue print item (b, item needs to be manufactured in accordance with PARFLUX specifications). 
01. FRAMEWORK SUBSYSTEM

1. 01001

2. Frame (Figs. 2 and $5 \mathrm{c}$ )

3,4. 1 1/2" diameter, class 6001-T6 aluminum pipe, schedule 40

5. $50 \mathrm{~m}$ per set (exact length needed; $48.8 \mathrm{~m}$ )

6. $\$ 1.37 / \mathrm{ft}$.

7. 0

8. Peter Frasse \& Co., Inc.

87 Ridge Ave. Ext.

Cambridge, MA. 02140

9. $\mathrm{s}$

1. 01002

2. Pipe fittings (Figs. 2 and 5 )

3-7. 1 1/2", schedule 40 rated marine grade (6001) molded aluminum Hollander Structural. fittings for 1 1/2" pipe. Hollander \#10 TSD CORNER, 12 ea., $\$ 7.90$ ea. Hollander \#20 CROSS, 16 ea., \$5.28 ea.

8. Babbit steam \& Specialty Co.

800 Mt. Pleasant Street

New Bedford, MA 02745

9. $\mathrm{s}$

1. 01003

2. Floatation spheres (Figs. 2d and $5 d$ )

3. Pyrex ${ }^{R}$ glass sphere with $A B S$ resin hard-hats

4. $43 \mathrm{~cm}$ diameter glass sphere encased in plastic hard hat used for floatation. Spheres must be tested (by factory or in the field) at 17,000 psi. Regular lib-hats are recommended.

5. 8

6. Spheres, BENTHOS 2040-17V, $\$ 276$ ea: hats, BENTHOS $204 \mathrm{HR}-17$, $\$ 48$ ea.

7. 0 ( $1 / 4$ number of trap inventory)

8. Benthos Inc.

Edgerton Drive

North Falmouth, MA 02556

9. S

1. 01004

2. Pressure-case retaining stand (Figs. 2 and 5, supports f)

3. $1 / 2^{\prime \prime}$ aluminum sheet stock

4. Blue prints available for the following items: 1. For BENTHOS 885-2 time release, $1 / 2$ " aluminum sheet is cut to $12^{\prime \prime} \times 27^{\prime \prime}$ and welded in crossing the two tubings at the bottom. A pair of aluminum stands with 1/8" thick aluminum straps hold the electronics pressure case. stainless steel case and aluminum stand/strap are 
insulated with $1 / 16^{\prime \prime}$ Neoprene ${ }^{R}$ sheet. 2. for OISWilliams time release (aluminum casing) a pair of aluminum stands are welded to the inside of a vertical member of tubing. Pressure case is strapped by aluminum $1 / 8^{\prime \prime}$ thick bands.

5. 1 set aluminum straps

6. 0 ( $1 / 4$ number of trap inventory)

9. b

1. 01005

2. Hose clamps (Figs. 2d and 5d)

3. 314 or 360 stainless steel

4. Assortment of large sized hose-clamps ranging from $\mathrm{M} 60$ to MI04 is required to hold floatation spheres connecting hardhats to the framework. This avoids swaying of

5. 16 to 20

6. 4

8. Aeroseal ${ }^{R}$, QS200, M60 to M104. Manufactured by Breeze, Inc., Union, N.J. Local hardware shop.

9. $\mathrm{s}$

1. 01006

2. Zinc anode (Figs. $2 \mathrm{c}$ and $5 \mathrm{c}$ )

3. Zinc nigot

4. $1 / 81 \mathrm{~b}$. and $1 / 16$ zinc ingret is fastened to stainless steel I shaped steel holder. Attached to the lower part of the aluminum ( $1 / 8$ lb.) tubings and a pressure case ( $1 / 16 \mathrm{lb}$.$) for up to 4$ months deployment.

5. $41 / 8$ lb., $11 / 16$ lb.

6. $21 / 81 b$.

9. b

\section{COLLECTOR Subsystem}

1. 02001

2. Sediment trap funnell (Figs. $2 \mathrm{~b}$ and $5 \mathrm{~b}$ )

3. PVC, Trovidour ${ }^{\mathbb{R}}, 3 / 8^{\prime \prime}$ sheet stock

4. (Order specification) Opening (ID): $140 \mathrm{~cm}$ top and 10 $\mathrm{cm}$ bottom. Frustrum height $170 \mathrm{~cm}$. Material is $3 / 8$ " thick Trovidour and heat processed as per agreed, single structure. Top and bottom finished flat. Seam lines on a frustrum must be less than 3 and joined by 4 corner/ 45 degree/double welding method. Polished inside as per instructed. Accessories to be included in this order: 4 ribs of two plates for an choring are $1 / 2$ " Trovidour 4 and welded to the frustrum as per requested. 


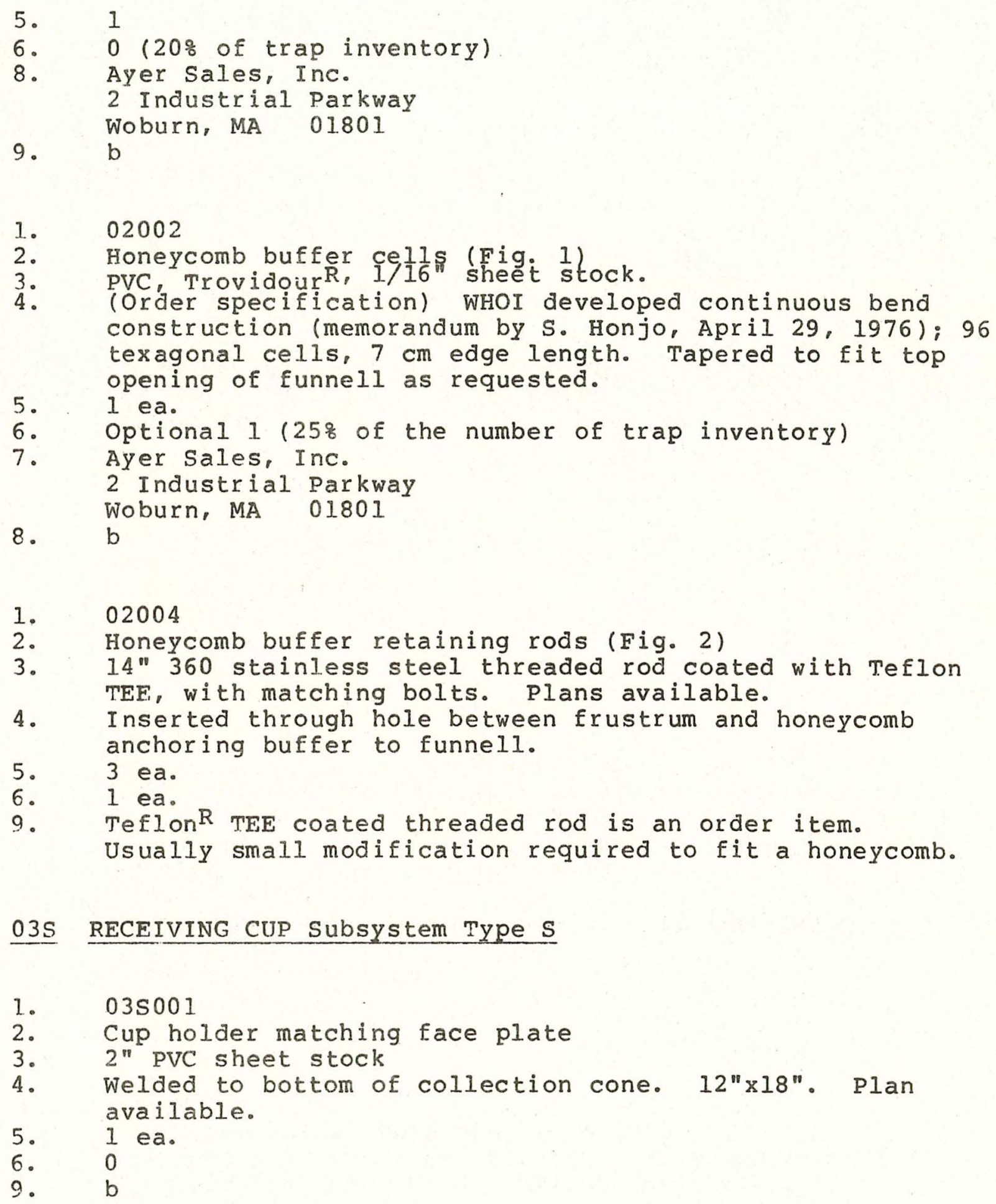




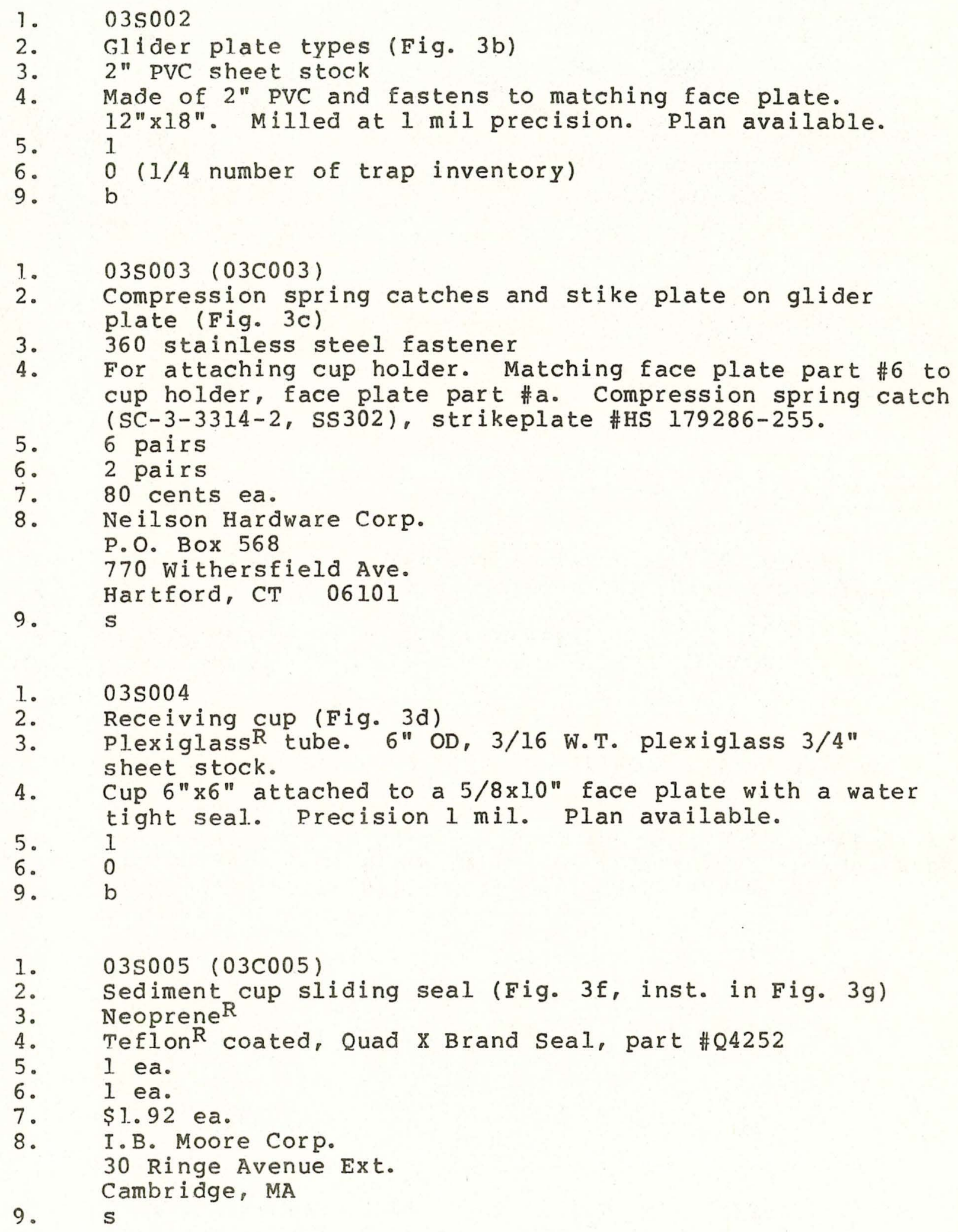




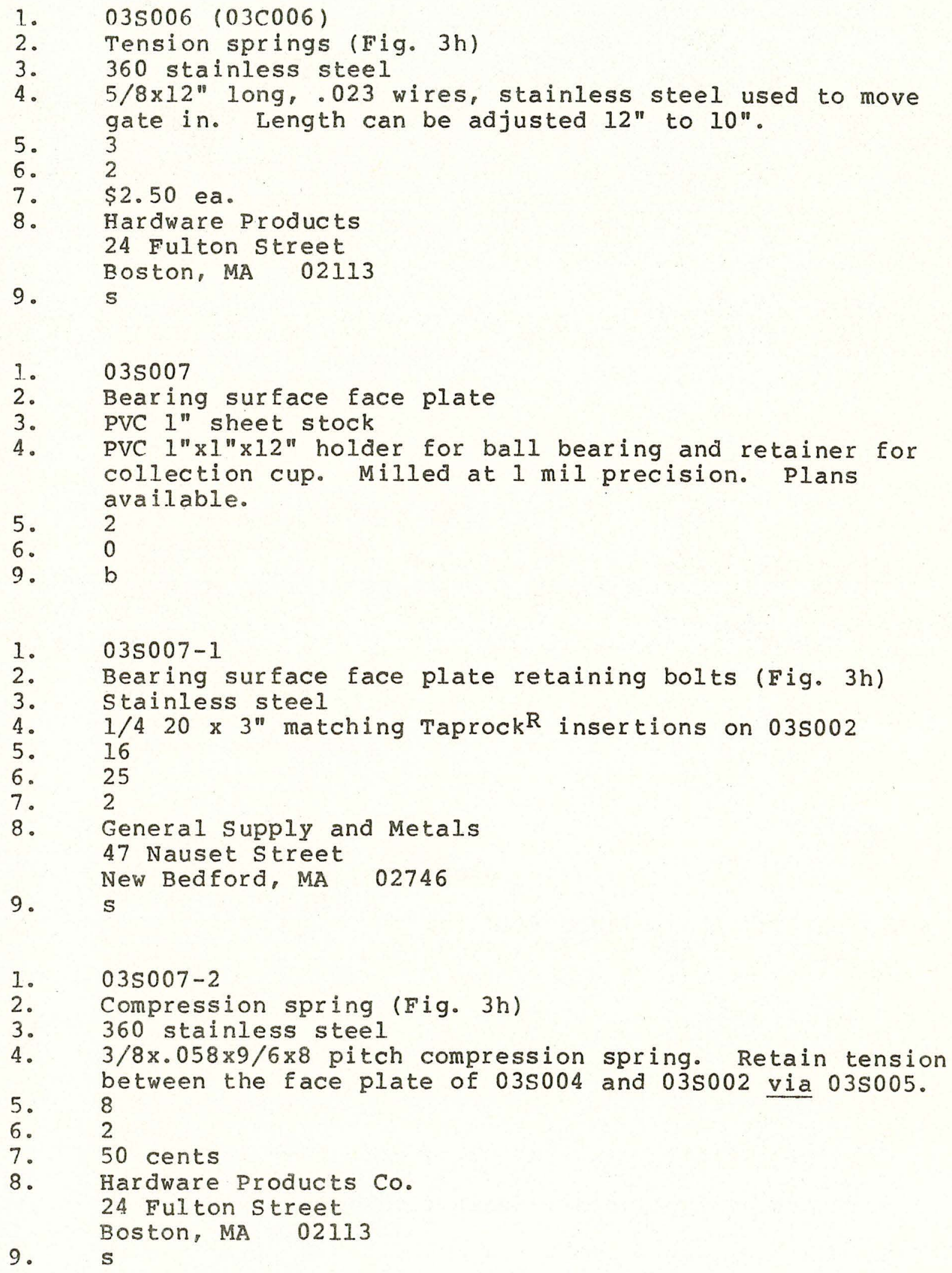




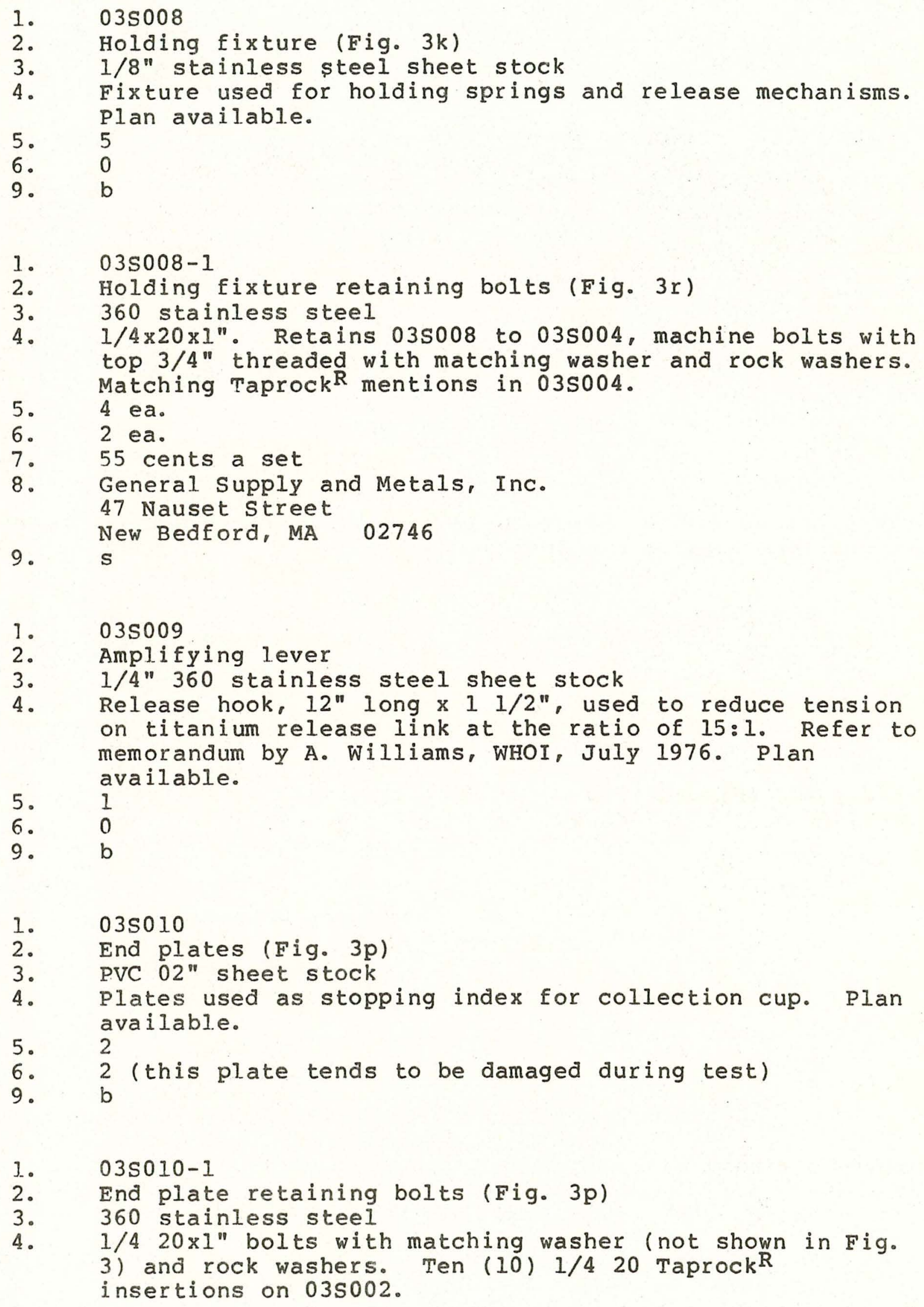




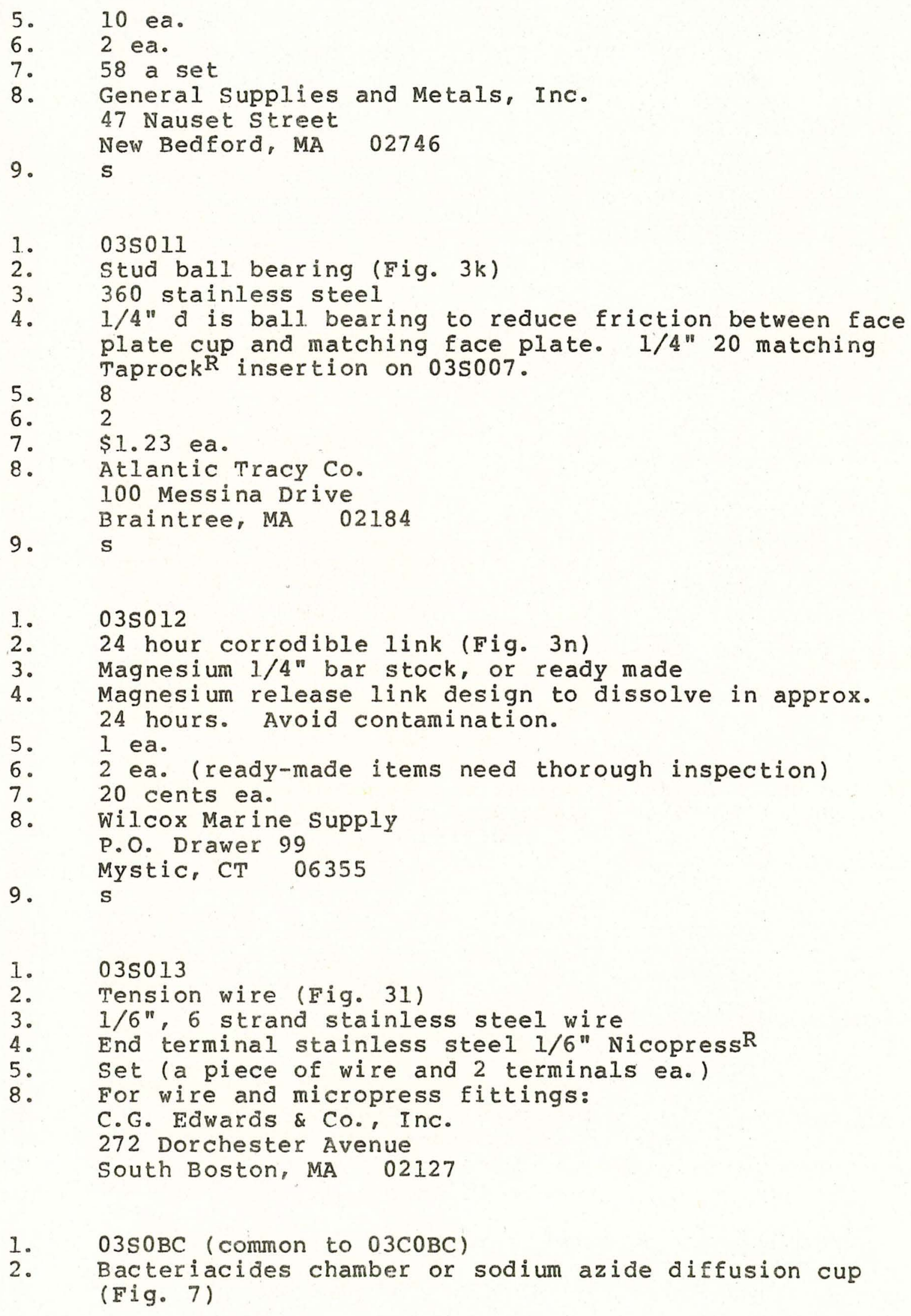


3. Lucite $R$ or PlexiglassR, $23 / 4^{\prime \prime}$ bar stock

4. $6.5 \mathrm{~cm}$ in diameter (OD), $7 \mathrm{~cm}$ high and $3 \mathrm{~mm}$ wall

thickness cup. One end is closed and the other is fitted with a

$47 \mathrm{~mm}$ membrane filter retainer (Nucleopore $\mathrm{R}^{\mathrm{R}}$ ). Plan available.

5. 1

6. Require spare filters. $\mathrm{NaN}_{3}$ (reagent grade) and $\mathrm{NaCL}$ is consumptive.

9. b

-- IMPORTANT: READ APPENDIX OF THIS REPORT FOR SAFETY PRECAUTIONS FOR HANDLING SODIUM AZIDE ( $\left.\mathrm{NaN}_{3}\right)$--

03C RECEIVING CUP subsystem Type C

1. $03 \mathrm{COO} 1$

2. Mounting plate, Type C plate (Fig. 6a)

3. PVC 2" sheet stock

4. Made of $2^{\prime \prime} \mathrm{PVC}$ and welded to bottom of collection cone. No milling required. Plan available.

5. 1 ea.

6. 0

9. b

1. $03 \mathrm{C} 002$

2. GIider plate, Type C (Fig. 6b)

3. Matching PVC sheet stock

4. Fastens to matching face plate and houses two sliders.

Milled at 1 mil precision plan available.

5. 1

6. 0 (20\% number of traps inventory)

9. b

1. $03 \mathrm{C003}$

2. Compression spring catch and strike plate on glider plate (03C002) ( $\mathrm{Fig} .6 \mathrm{C}$ )

3. $\quad 360$ stainless steel

4. Fastener for attaching cup holder matching face plate part $b$ to cup holder face plate part a. Compression spring catch SC-3-3314-2, SS302, strike plate \#HS179286-255.

5. Neilson Hardware Corp. P.O. Box 568

770 withersfield Avenue

9. 5

Hartford, CT 06101 


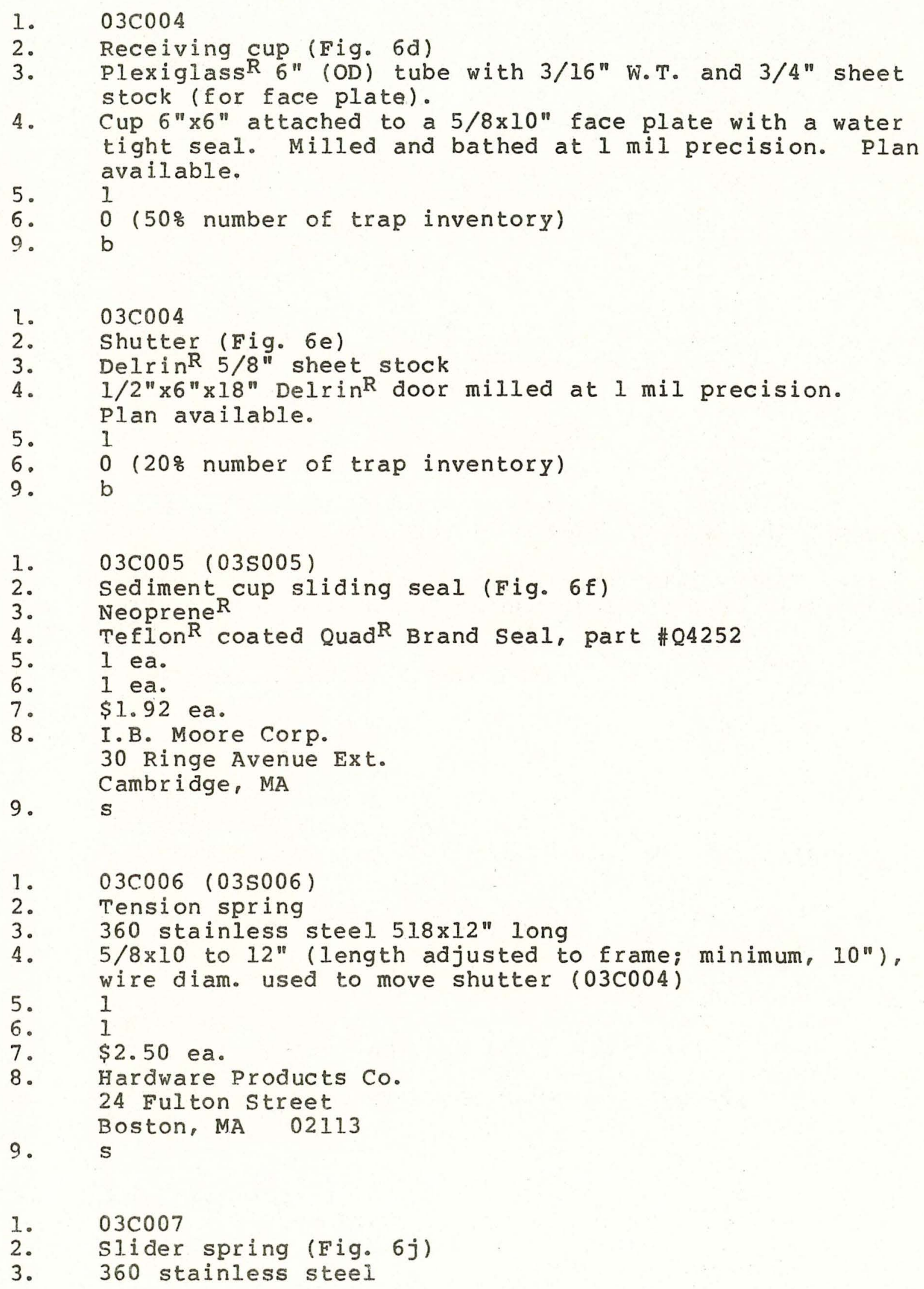




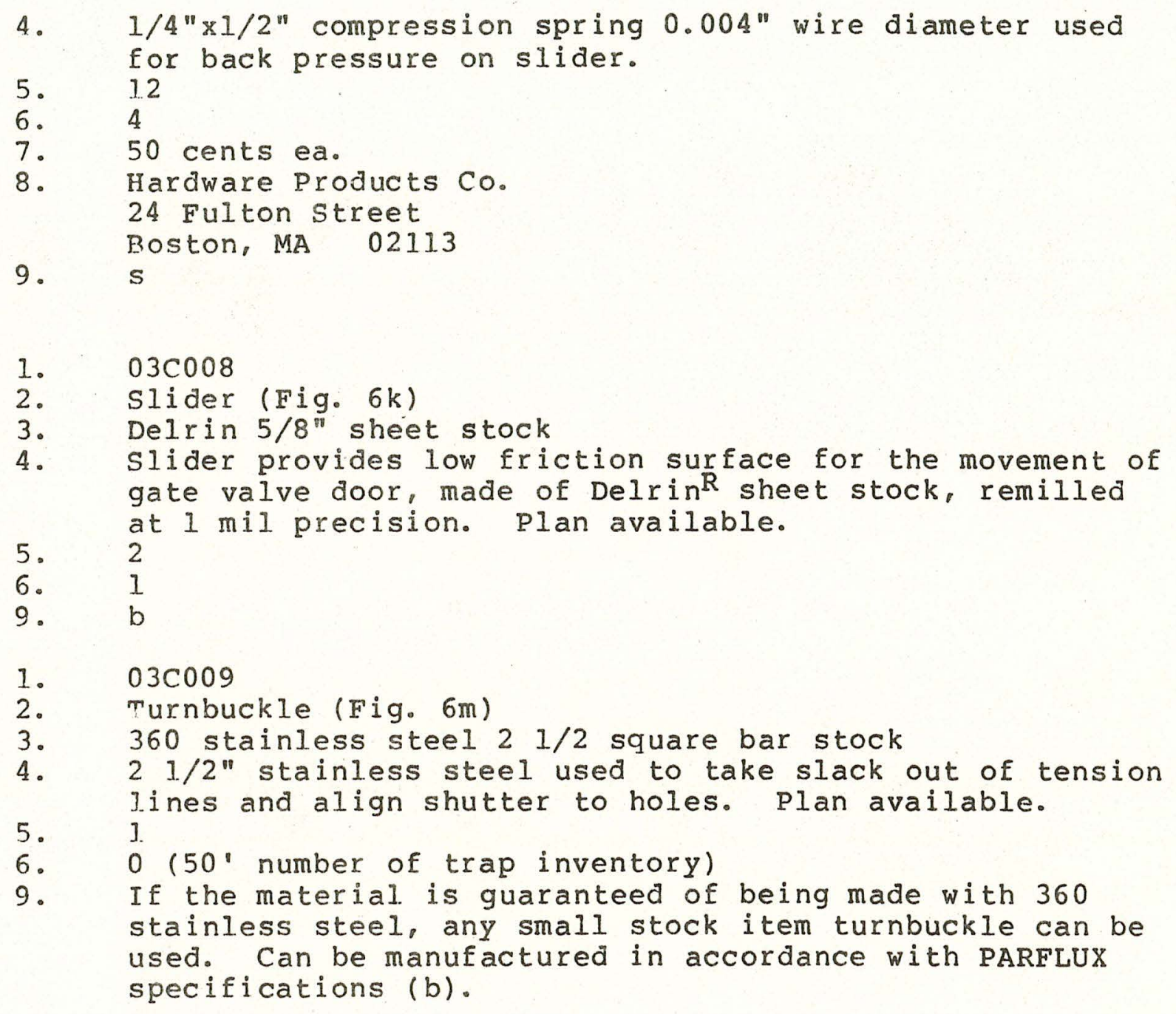

1. $03 C 010$

2. End plate (Fig. $6 \mathrm{~h}$ in Fig. 6e)

3. 360 stainless steel $1 / 8^{\prime \prime}$ sheet stock

4. Fixture used to hold hardware to end of gate valve. 10

5. 2

6. 0

9. b

1. 030011

2. Holding pulleys for burnwire link (with burnwire, Fig. $6 \mathrm{~g}$ )

3. 314 stainless steel tackle block

4. Marine grade, 1/4" diameter

5. 2 ea.

6. I ea.

7. $\$ 4.20$ ea. 


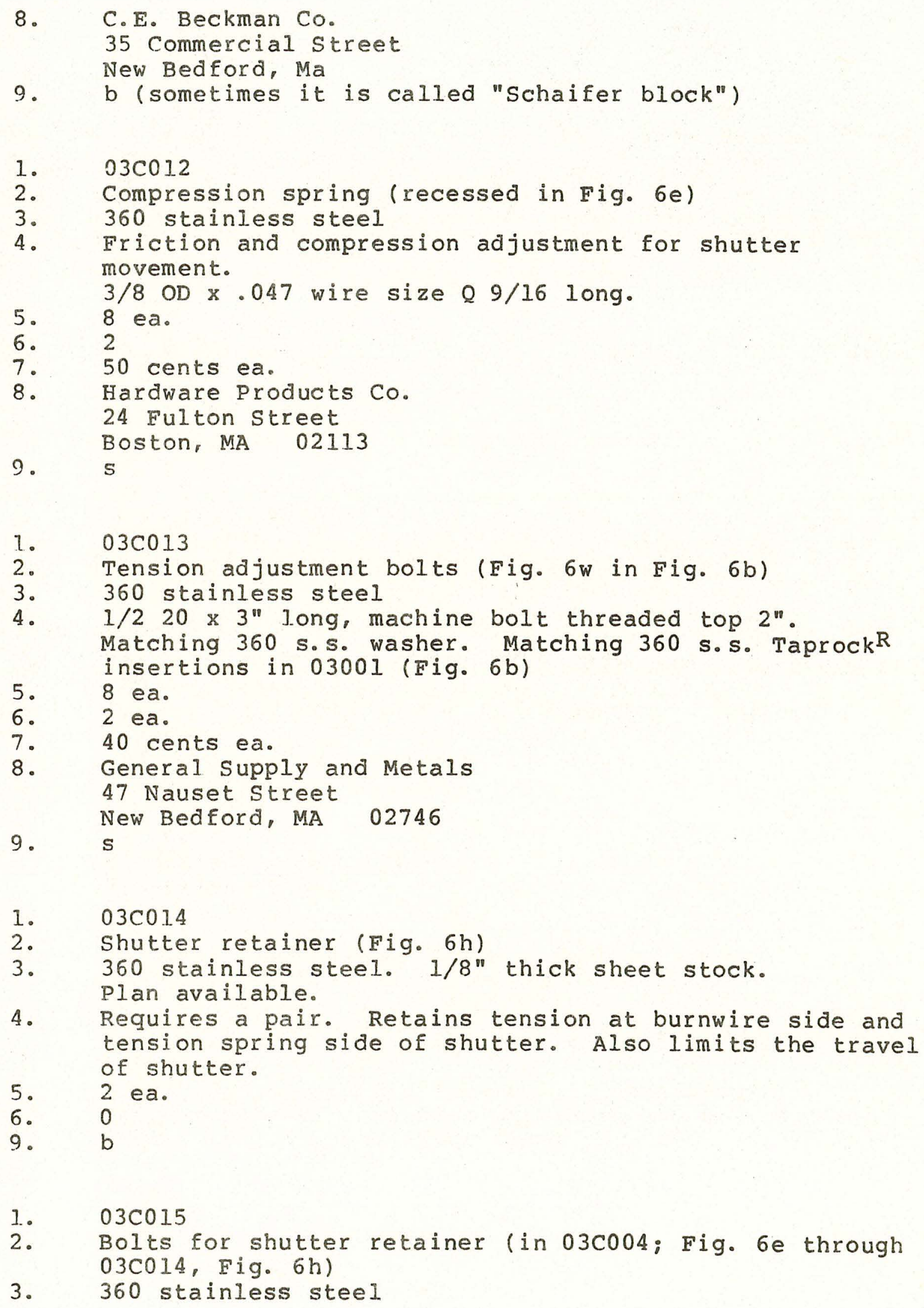


4. Fix shutter retainers at both sides of the shutter. 1/4-20xI", with matching s.s. washer and rock washer.

6. 8 ea. (only 4 are shown in Fig.).

7. 66 cents ea.

8. General Supplies and Metals, Inc. 47 Nauset $\mathrm{S}$ treet New Bedford, MA 02746

9. S

04 TIMER FLECTRONICS Subsystem

1. 04001

2. Timed Releases

4. Crystal. controlled electronic timed burnwire release, BENTHOS 855-2, precision $0.025 \%$ at $2^{\circ} \mathrm{C}, 9$ seconds to 4.6 days. Stainless steel pressure house to be tested to 17,000 psi for one hour. Fixed with the stand to framework with $1 / 2$ " aluminum plate with helium welding. Plan for stand available.

5. I ea.

6. BENTHOS 855-C circuit board, a spare set of alkaline batteries as requested.

7. $\$ 2,680$

8. Benthos, Inc. Edgerton Drive North Falmouth, MA 02556

9. 5

1. 04001

4. Also OSI-Williams Timed Release

7. $\$ 544$, Pinger release $\$ 9158$

8. Oceanographic Instrument Systems, 14 Overy Driave, Box 766, North Falmouth, MA 02556.

9. S

1. 04002

2. Burnwire (or releasing link) BENTHOS 855-ST or 855-2TR

3. \#16, single stand titanium wire with Neoprene insulation.

4. 10" long \#16 Ti-wire is formed into a loop by electron beam welding the ends. The loop is hot-coated with $1 \mathrm{~mm}$ thick Neoprene $\mathbb{R}^{\mathbb{R}}$ insulation leaving a $1.5 \mathrm{~mm}$ slit leaving titanium wire exposed for dissolution. Momentary tensile strength loop should be tested at 125 Ib.

5. 1 ea.

6. 1 ea.

7. $\$ 92.00 ; 855-2 \mathrm{~T} ; \$ 52.00$ refurbishment, $855-2 \mathrm{TR}$

8. Benthos, Inc.

Edgerton Drive North Falmouth, MA 02556

9. 5 
Explanation of Plates

Plate 1. Photograph of a PARFLUX Mark II type s sediment trap. Upper photograph: side view when laid horizontally. Honeycomb buffer (not seen) is on the left side. Lower photograph: bottom view looking upward as being deployed. The receiving cup in "open mode".

Plate 2. Close up photographs of receiving cup moving mechanism. Alphabetical identification of parts correspond to Figure 2. Upper photograph: magnesium corrodible link (n) and a turnbuckle (m) are seen. Lower photograph: double spring side, an amplifying lever $(r)$ with insulated titanium wire $(q)$ is shown.

Plate 3. Deployment sequence $(A-D)$ and partial view of type C traps.

A. A PARFLUX trap is affixed to a taut line with buoyancy spheres (b). Traps can be deployed through A-frame (a) or a crane.

B. An upper tautline $(t)$ should create a moderate pulling strength of a few hundred pounds during deployment. A trap is lifted from the deck via a set of side lines (c).

C. Remote control latch (e) is released at the moment when the upper part of the trap starts to be submerged.

D. A trap is now deployed in the water and is semisubmerged showing honeycomb buffer $(h)$ and stay surface till an anchor starts to settle.

E. Partial view of type C receiving cup. j. shutter, g. receiving cup (no bacteriacide chamber is seen $n$ this photo): E. aluminum frame; and $k$. a fixture.

F. A timer release is mounted on an aluminum plate which is welded on a frame. Two insulated wires (w) feed electricity to a burnwire loop via timer electronics.

G. Photograph of burnwire-side of type C receiving cup mechanism. v. Titanium burnwire; r. turnbuckle covered with black tape to prevent spontaneous turn. 
H. Recovered sediment in type $C$ receiving cup before covered with a PVC protective lid. C. Quad- $x^{R}$ sealing ring; $q$. bacteriacide chamber.

I. A photograph viewing inside of a receiving cup after recovery. m. filter holder of bacteriacides chamber; s. collected sample.

Plate 4. A. Fresh surface of polyvinyl chloride (PVC; Trovidour ${ }^{R}$ ) under SEM. $X 10,000$.

B. Same as A after 283 (accumulative) days of deployment along with the $\mathrm{S}_{2}$ and $\mathrm{E}$ arrays. Essentially the surface is intact. Small white spots are possibly sea-salt. X 10,000.

C. Fresh surface of type 600 (marine grade) aluminum. After $\& 500$.

D. After a long deployment, the thin veneer of surface was covered by dehydrated film. No structural weakness or fatigue was observed on the aluminum frames up to 344 accumulative days of deployment at $400 \mathrm{~m}$ or bathpelagic water. $x$ 500.

E. Fresh surface of type 360 stainless steel. surface of a cold milled, v2 bolt. X 800 .

F. Same material as E. After 344 days of accumulative deployment at bathypelagic layer. 

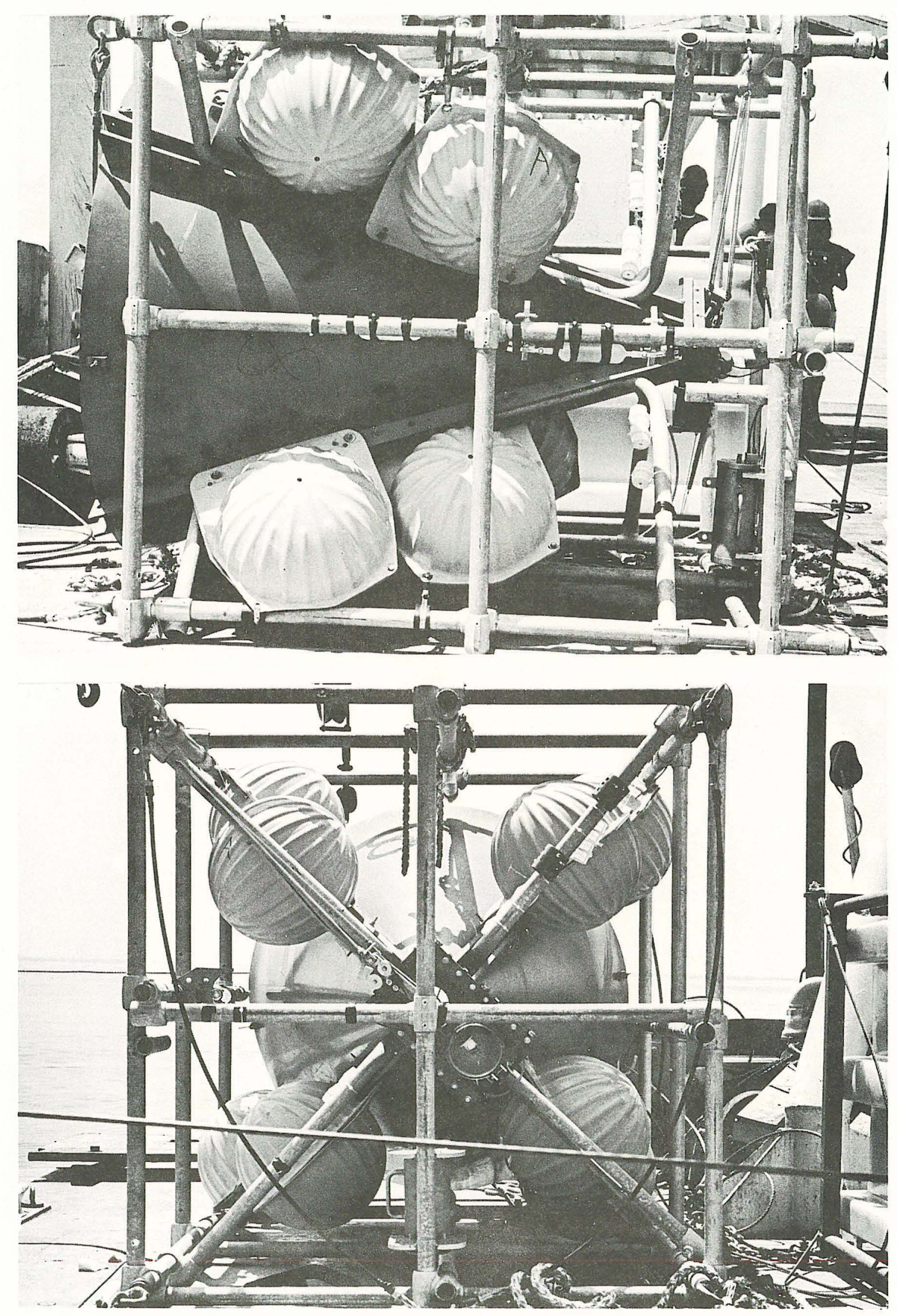

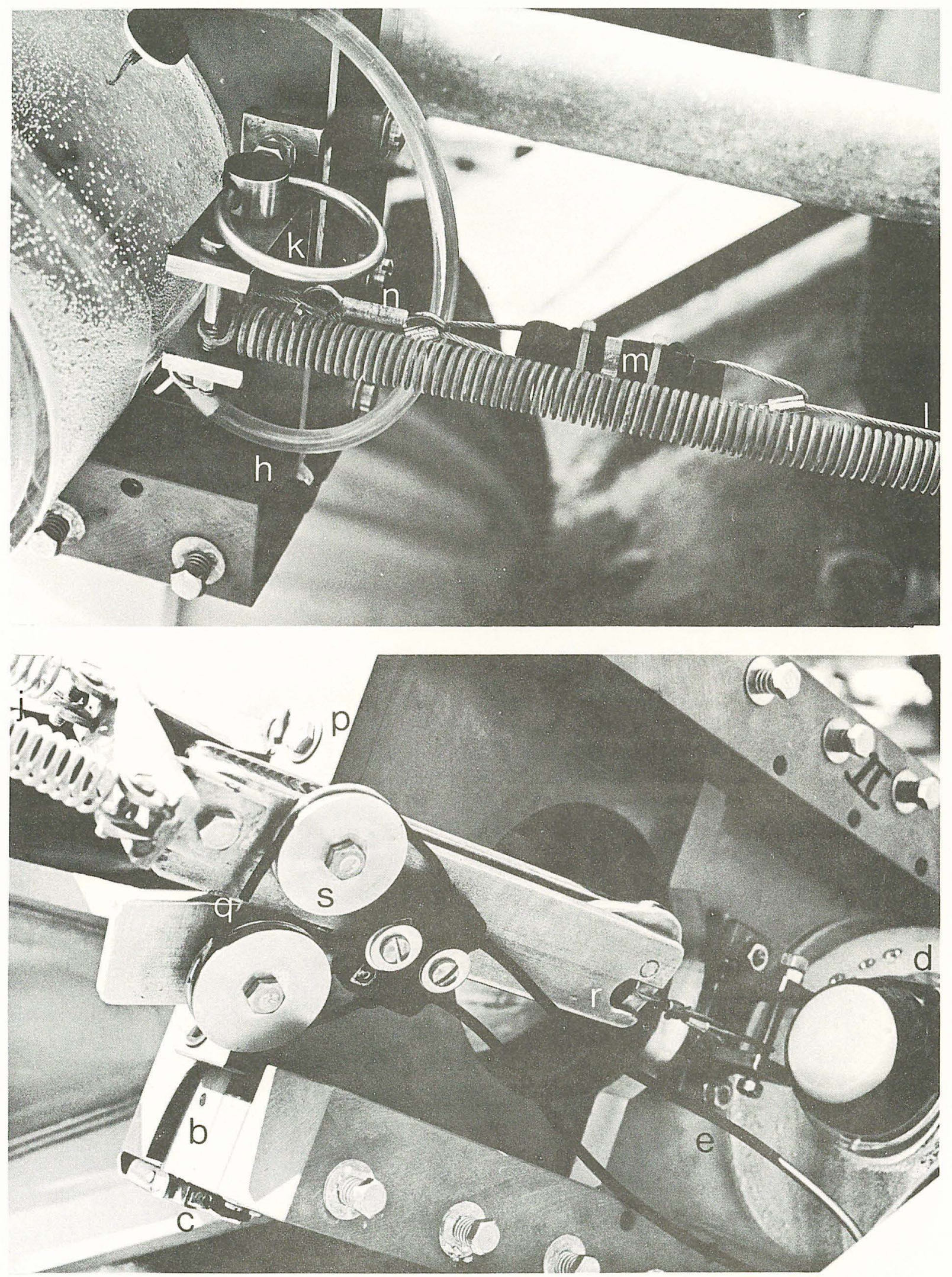

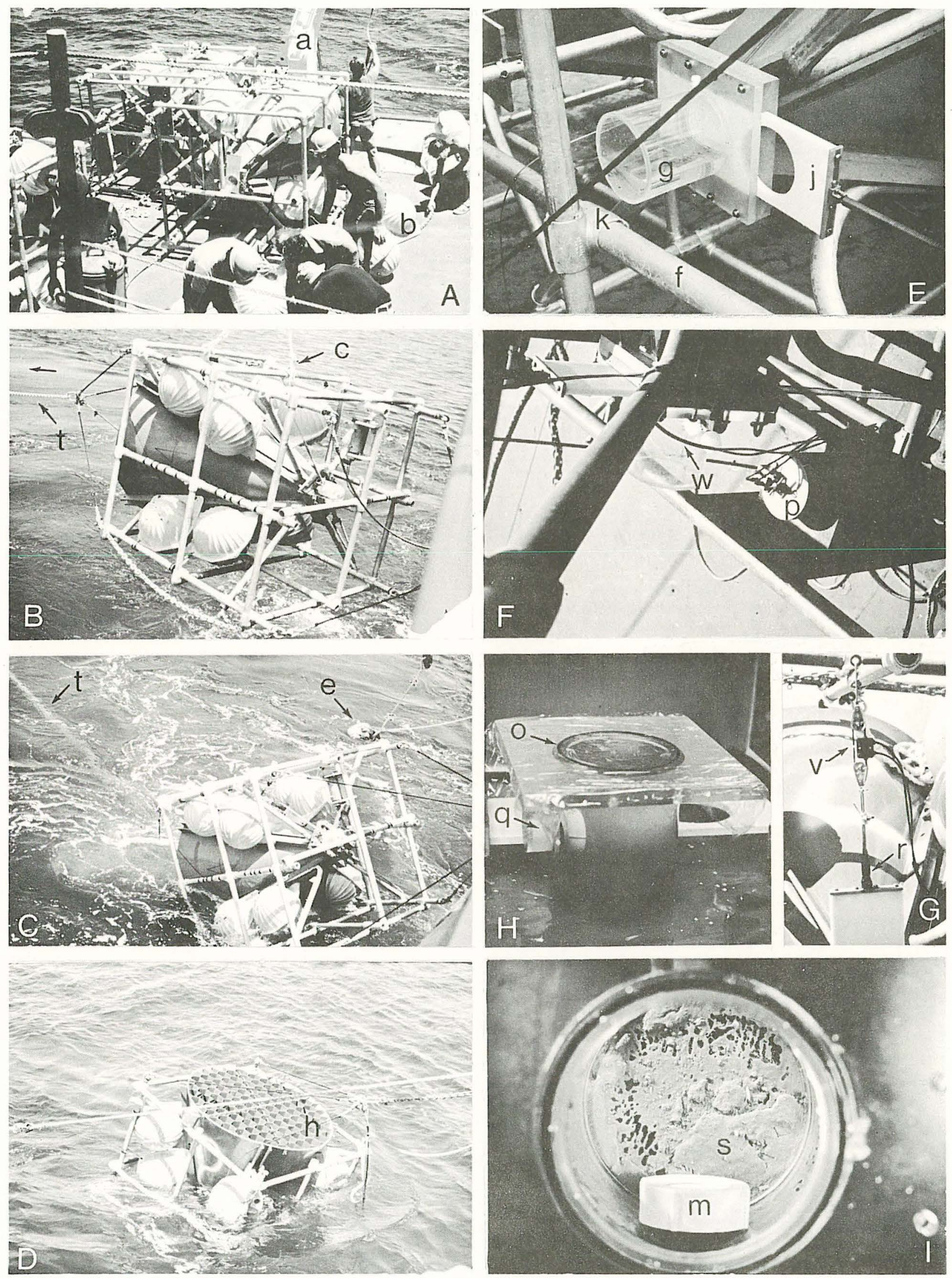

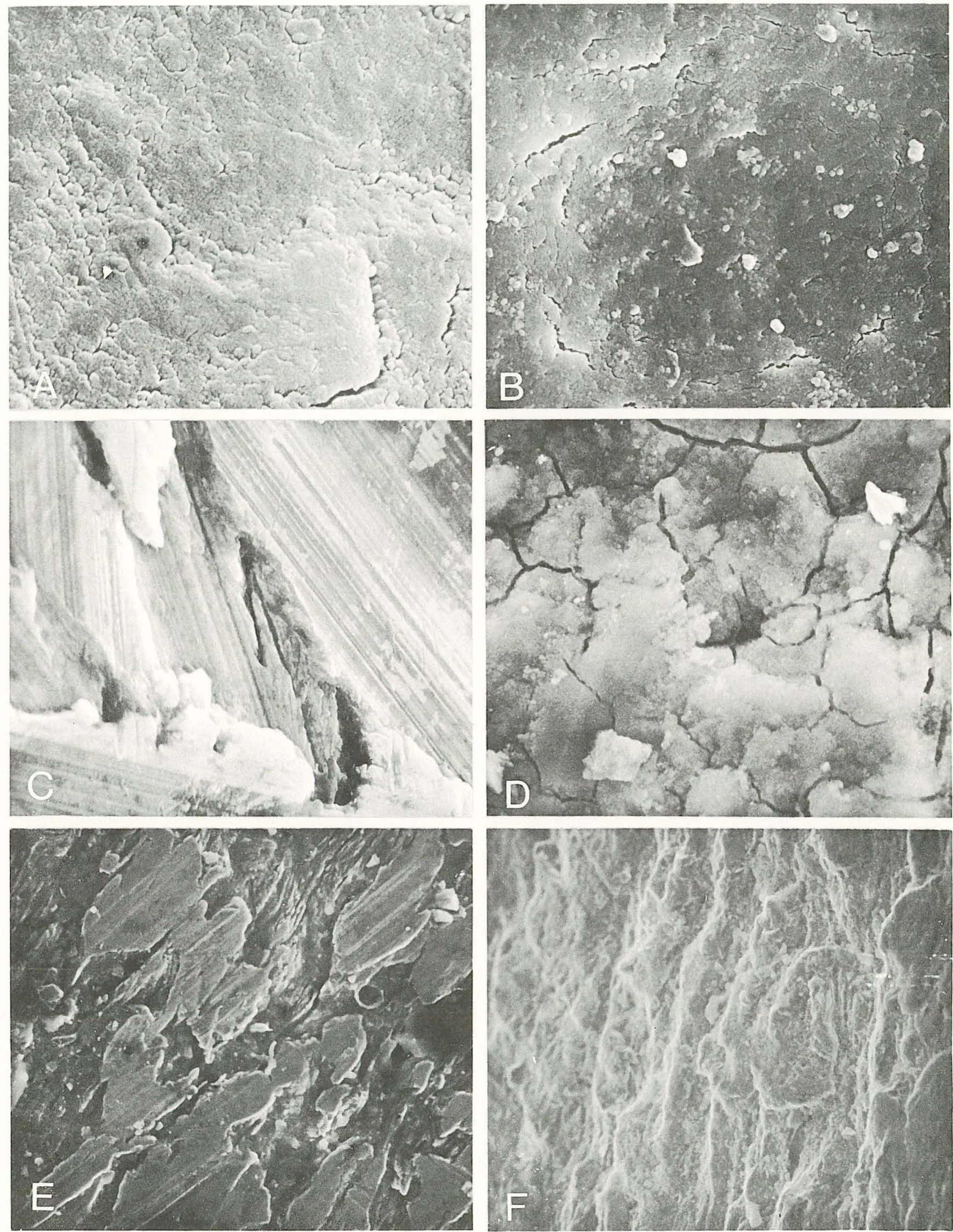
Sodium azide $\left(\mathrm{NaN}_{3}\right)$ is a powerful enzyme inhibitor ( $\mathrm{Fe}^{+++}$protoporphyrin enzymes) (e.g. White et al., 1968, Principles of Biochemistry, p. 239). It is generally recognized that the water/sea-water solution with $0.01 \%$ sodium azide inhibits microbial growth. It has been clear that sodium azide is hazardous in terms of strong toxication to the human body as well as it forms a detonating compound meeting with common metals such as copper and lead. A few hundred grams of undiluted sodium azide is used for a bacteriacide diffusion chamber for each deployment of a PARFLUX sediment trap. We feel it is important that sodium azide be used properly in preventing possible accidents.

There are three causes of hazard in the use of sodium azide: 1) toxicity to the human body by direct contact or acified gas; 2) contamination of sewage water may stop the microbial degradation of waste in the system; and 3 ) formation of explosive matter by aquatic or non-aquatic contact with certain metals. We propose that sodium azide should, regardless of the amount to be used, be treated with extreme caution particularly on board a research vessel.

1. Sodium azide is assigned as a type B hazardous matter. Transport and storage of this material should be rendered in accordance with the regulations imposed by the Department of Transportation.

2. Report to the chief scientist the possession of sodium azide. Storage in laboratory; never leave outside of the scientific area.

3. Well protect the bottle and clearly label it. Any possibility of spillage of poweder should be avoided. If it is diluted, clearly describe the percentage.

4. Be extremely careful to avoid direct contact with skin. Avoid any possible inhalation of undiluted powder.

5. Avoid on-board exposure of undiluted sodium azide as much as possible. If necessary, work on $4 \mathrm{mil}$ plastic sheet, at least $3^{\prime} \times 4^{\prime}$, spread on a bench as far from the ventilation registers as possible. When a job is completed, the plastic sheet should be folded carefully and sealed in a small plastic bag and bring for on-shore incineration. Do not contaminate door knobs, etc., with your hand. Take a shower as soon as possible after handling it. 
6. Do not drain the solution at any dilution into the ship"s or laboratory's sink. Do not contaminate the biogenic sewage system.

7. Regardless of the amount of dilution, avoid any possible contact with any kind of acid solution. keep away from lead acid batteries.

The following is a partial citation from: Fire protection Guide on Hazardous Materials, p. 491M-377, 7 th ed. (1978), National Fire Protection Association, 470 Atlantic Avenue, Boston, MA 02210 .

SODIUM AZIDE $\left(\mathrm{NaN}_{3}\right)$

(self-reactive) Sodium azide decomposes at $275^{\circ} \mathrm{C}$. Mellor 8 ; supp. 2: 43 (1967)

Benzoyl Chloride and The mixture of sodium azide and Potassium Hydroxide

benzoyl chloride reacts spontaneously with evolution of heat in a potassium hydroxide solution. Mellor 8, Supp. 2: 55 $(1967)$.

Chomyl. Chloride The reaction of sodium azide and chonyl chloride is an explosive one. Mellor 8, Supp. 2: $36(1967)$.

Copper A solution of sodium azide in copper pipe with lead joints formed copper azide and lead azide, both detonating compounds. Klotz (1973).

Dibromomalononitrile These materials react to produce a product that is extremely sensitive to light shock. MCA Case History 820 (1962)。 A $\overline{\text { SESB }}$ Expl. Report 89 (1962).

Dimethyl sulfate During preparation of methyl azide from reaction of these two chemicals, a violent explosion occurred. Apparently the $\mathrm{pH}$ was allowed to fall below 5. At this activity hydrazoid acid, a powerful explosive, readily forms. MCA Case History 887 (1963).

Lead See SODIUM AZTDE plus Copper.

Nitric Acid The reaction of sodium azide and strong nitric acid is energetic. Mellor 8, Supp. 2: 315 (1967).

Citation from: Clinical Toxicology of Commercial Products. 3rd ed., 1969 (Gleason, M.N., Gosselin, R.E., Hodge, H.C. and Smith, R.P.). The Williams \& Wilkins Co., Baltimore.

AZIDE SALTS Induced methemoglobinemia affords Sodium azide limited protection to animals 
Hydrazoid acid acutely poisoned by azide. Since no other specific antagonists are presently recognized, a clinical trial is perhaps justified in a severe systematic intoxication. If so, proceed at once with the measures under CYANIDE in section II, omitting only the thiosulfate injections.

Hydrazoic acid is used in industry to prepare heavy metal azides for shel.1 detonators. The water soluble salts are not nearly so explosive. Workers exposed to this volatile acid for 15 yrs. showed no pathological signs. The vapors and fumes, however, are irritants of mucous membranes and heavy exposure has caused bronchitis and pulmonary edema. The azide ion is recognized as an inhibitor of heme iron enzymes, notably cytochrome oxidase, catalase and peroxidase. As with cynamide, the chief danger in acute exposures is probably a fulminating histotoxic anoxia. Azide stimulates the chemoreceptors of the carotid body. It is even more potent than sodium nitrite as a directly acting peripheral vasodilator which may complicate attempts to antidote azide intoxication by nitrite. (see also: CYANIDE and HYDROGEN SULFIDE. Reference Congeners in section III.) Ref.: Abbanat and Smith, 1964; Graham et al., 1948: Graham, 1949.

Partial citation from: Summary Report, ASCP Commission on Continuing Education, 2100 west Harrison Street, Chicago, Illinois 60612 .

Explosion Hazard - A Solution by C. Broadbridge, B.C.R. Lowes, Springfield Hospital Center, Springfield, Massachusetts 01107.

"We wish to make veryone aware of a potential laboratory hazard that exists with some laboratory reagents containing sodium azide.

This particular chemical is commonly employed in saline and other isotonic solutions employed with automatic cell counters, as a preservative agent. The diluting fluids used with automatic counters and cell washers contain $0.01 \%$ sodium azide and due to the large quantities of dilutent used, the effluent is usually discharged in a sink. Most sinks have copper or lead piping and the azide can form a very explosive compound with thes metals. The problem arises when a blockage occurs and an attempt is made to remove it with a metal plumber "s "snake". Four instances of explosions have been reported and fortunately, no injuries have occurred, but obviously a real hazard exists. 
We would recommend the following procedure for all laboratories allowing sodium azide to be discharged through copper or lead pipes. Decontaminate the piping with nitrous acid after flushing with copious amounts of water. Replace all copper and lead plumbing with plastic pipeware. The old metal pipes should be cut away with pipe cutters and no attempt should be made to undo the joints."

Azide and Acid-Dangerous Mixture by E. L. Cohen, Presbyterian University of Pennsylvania Medical Center, Philadelphia, Pennsylvania, 19104 , April 1974.

"The January 1974 issue of Summary Report carries on page one a note on the explosion hazard which can result from disposing of solutions containing sodium azide via lead or copper waste lines. The note recommends decontamination of piping with nitrous acid.

Immediate attention of all laboratories should be called to the health hazard of azide compounds before too much acid treatment is used.

In addition to their instability and explosive nature, azide compounds under acid conditions yield hydrazoic acid. This latter compound is extremely toxic, producing vertigo, weakness and dangerous falls in blood pressure. Sodium azide has been used as a hypertensive, but its effect has been highly uncontrollable. While the azide content of our solutions is low (usually $0.01 \%$ or less), where build-up has taken place, large quantities can be present.

I believe that no acid should be used to decontaminate piping, and that azide compounds should no be allowed to contact acid conditions. The safest method of disposing of solutions containing azides is by high dilution with water before discharge to waste. The sink in which we dispose of such solutions has had the water tap washer cut so that the water flow can never be cut off. Under such conditions we have seen no build up of azides in piping.

My concern with and respect for azide compounds was learned personally the hard way, and the experience was not pleasant. At a minimum all persons using these compounds should carefully read the warnings required by law on the containers." 
APPENDIX 2 .

Electronics Timer Release

The following information on BENTHOS 855-2 Deep sea Light Load Timed Release was provided us by Mr. David Hosom, Benthos, Inc., North Falmouth, Mass., as was cited as "personal communication, publication by permission". We have also successfully used the OIS-Williams release as well.

Theory of Operation

This description refers to the block diagram in Appendix 2. In this circuit a crystal oscillator provides a frequency of $32,768 \mathrm{~Hz}$. Internal to the chip, the frequency is divided by $2^{15}$ (with the jumper in 81 position) to obtgain an accurate $1 \mathrm{~Hz}$ output. (When the jumper is moved to the $\mathrm{X} 2$ position, the frequency is divided by $2^{16}$ giving a $0.5 \mathrm{~Hz}$ output, thus doubling the delay time.) The I Hz output is fed into the first divide by 60 , resulting in an output of 1 pulse every minute. The output of this is in turn fed into the second divide by 60 , giving an output of 1 pulse every hour.

For testing, the test switch 52 bypasses both the divides delivering a $1 \mathrm{~Hz}$ output in place of the 1 pulse per hour output. When the jumper is moved to the "minutes" position, only the second divide is bypassed, resulting in a final output of 1 pulse per minute for higher resolution, short term deployments. The output signal is fed into the first of the four decade counters. The four counters form a unit capable of counting from 0000 to 9999. The four rotary switches for each decade determine where along this counting progression a release will be initiated.

When all the counters have reached their appropriate counts, the four inputs of the AND gate will be at a logic one state. When this signal goes high, the transistor turns on, supplying gate current for the silicon controlled rectifier which also turns on, grounding the housing, supplying a ground path by which the release wire begins to dissolve. In addition, the logic 1 output from this gate causes the oscillator and the first counter to be disabled, preventing any further counting from taking place, and ensuring that, once timed out, the output will remain high. 
specifications

Time delay adjustment: Settable on any hour from 0 to 9,999 hours (416 days) or Erom 0 to 19,998 hours (832 days). Jumper provides minutes instead of hours delay if desired.

Timing Accuracy: $\pm 0.01 \%$ (or better) of set delay ( 1 part in 8,000$)$.

Batteries: 24 separate batteries for high reliability; 9 volt alkaline (Mallory MN1604 Duracell).

Test Circuit: Built-in. Allows times to be cycled at a $1 \mathrm{~Hz}$ rate.

End Cap Connector: Joy \#X8372-103.

Connector Cable: Joy \#X8372-153.

Release Loop Material: $6 \mathrm{Al}-4 \mathrm{~V}$ titanium wire.

Housing Material: Hardened 17-4PH stainless steel.

Depth Rating: 12,000 meters.

Dimensions: $12.2 \mathrm{~cm}$ ( 4.8 inches) diameter by $32.7 \mathrm{~cm}$ (12) $7 / 8$ inc.)

Weight: $14.1 \mathrm{~kg} \mathrm{(31} \mathrm{pounds).}$ 


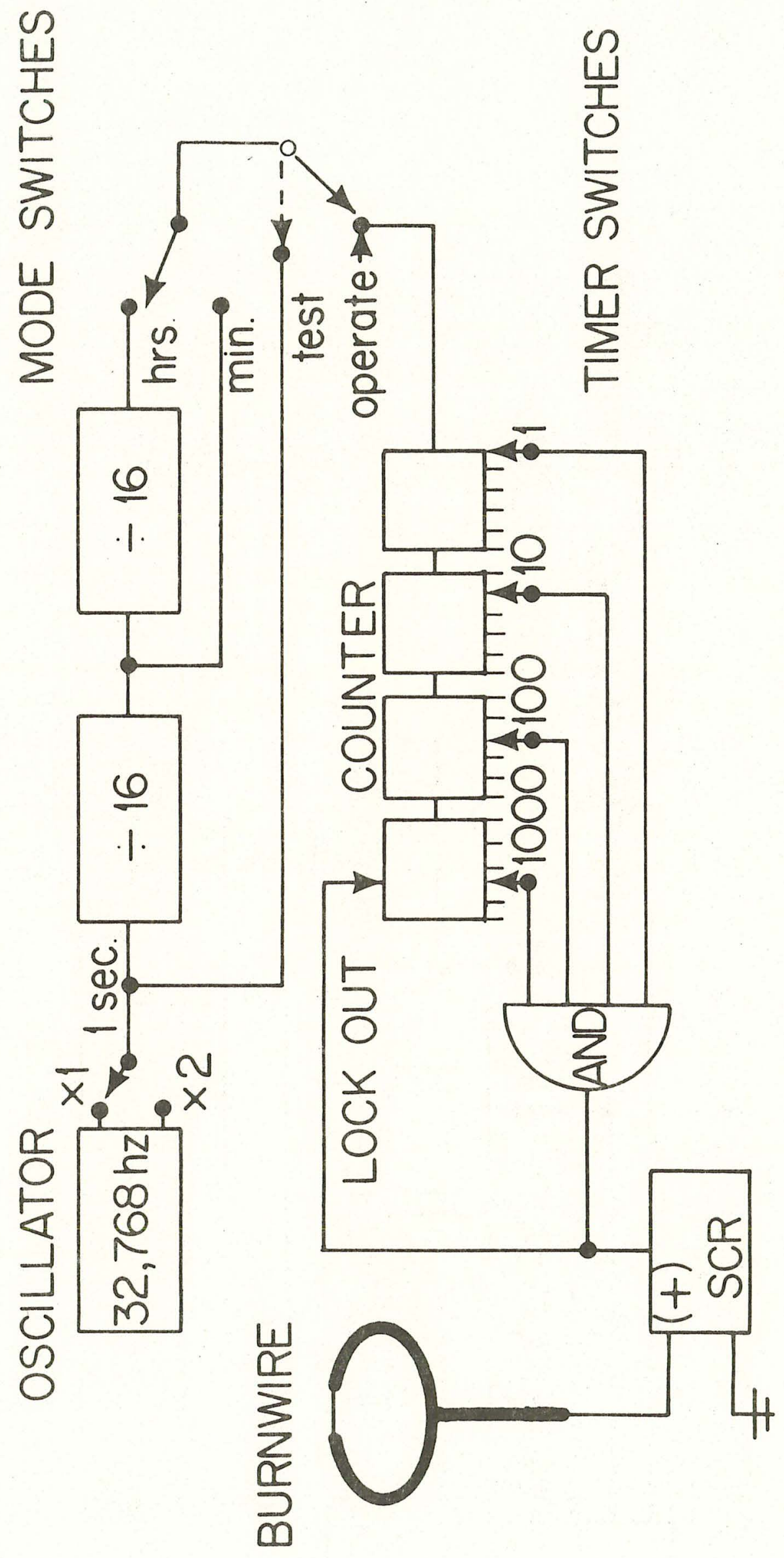




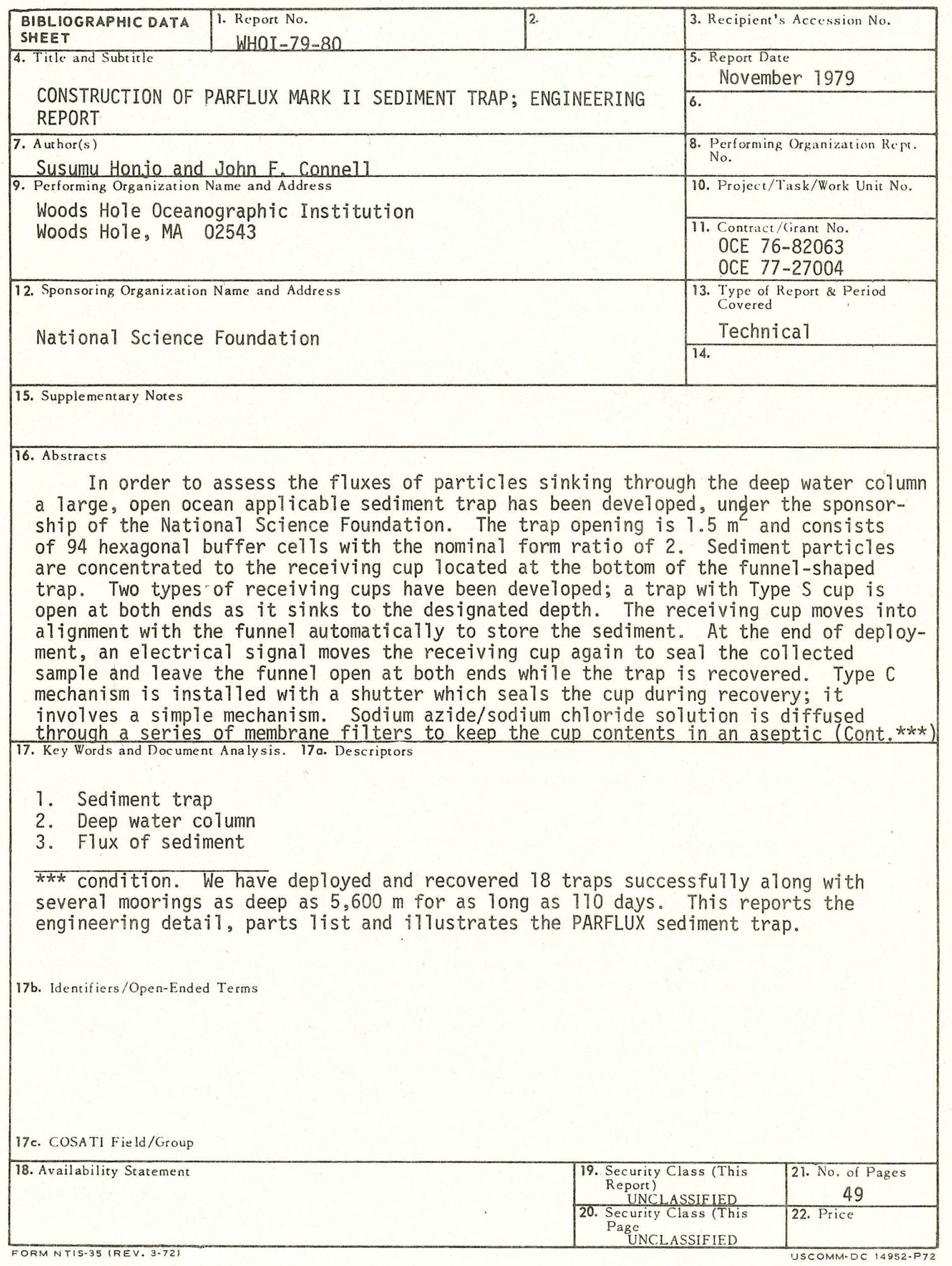




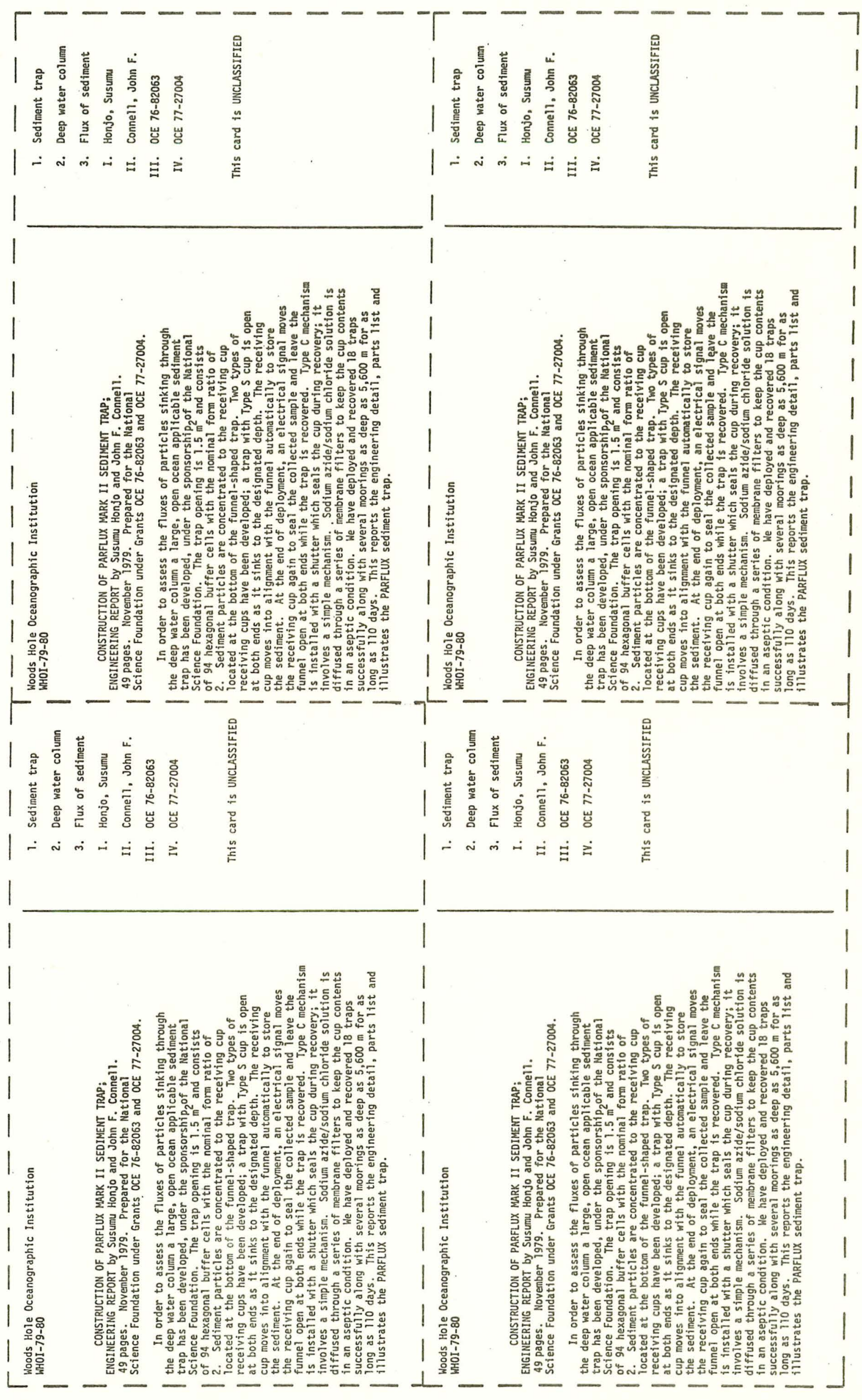

